\title{
Study of Crater in the Gobi Desert Induced by Ground Explosion of Large Amounts of TNT Explosive up to 10 Tons
}

\author{
Rongzheng Xu $\mathbb{D}^{1},{ }^{1}$ Li Chen $\mathbb{D},{ }^{2}$ Yuzhou Zheng $\mathbb{D},{ }^{1} \mathrm{Zhan} \mathrm{Li}^{1}{ }^{1}$ Mingjin Cao, ${ }^{2}$ and Qin Fang ${ }^{1,2}$ \\ ${ }^{1}$ State Key Laboratory of Disaster Prevention \& Mitigation of Explosion \& Impact, Army Engineering University of PLA, \\ Nanjing 210007, China \\ ${ }^{2}$ Engineering Research Center of Safety and Protection of Explosion \& Impact of Ministry of Education, Southeast University, \\ Nanjing 211189, China \\ Correspondence should be addressed to Li Chen; chenli1360@qq.com and Yuzhou Zheng; universe2009@126.com
}

Received 5 August 2021; Accepted 30 November 2021; Published 13 December 2021

Academic Editor: Chang-Ping Yi

Copyright ( 2021 Rongzheng Xu et al. This is an open access article distributed under the Creative Commons Attribution License, which permits unrestricted use, distribution, and reproduction in any medium, provided the original work is properly cited.

\begin{abstract}
Explosion craters on the ground surface induced by contact or near-field explosions have important implications, which can be used to assess blast consequences, guide the design of the explosion, or develop a protective strategy. In this study, to understand the crater characteristics induced by the contact explosion of large weight explosives, four field contact explosion tests were conducted on the surface of the Gobi Desert with large TNT charge weights of 1 ton, 3 tons, and 10 tons (test conducted twice). Cratering on the ground surface generated by large amounts of explosives was measured and evaluated, including the shape, depth, and diameter. A fine-mesh numerical model was developed and validated on the AUTODYN software platform, and a detailed parametric study was performed on the resulting craters. The effects of sand and gravel density, initiation method, shear modulus, and failure criteria were analyzed and discussed. An energy conversion coefficient was determined, and the corresponding theoretical equations were derived to predict the dimensions of the craters resulting from the large weight contact explosion. The calculated cratering characteristics were consistent with previous data and hence can be used in future engineering applications.
\end{abstract}

\section{Introduction}

An explosion on or near the surface of the ground creates a crater. The information about craters, for example, the crater's shape, diameter, and depth has been used to investigate the TNT equivalent observed in the Tianjin port explosions [1], Xiangshui explosions [2], and Beirut port explosions [3]. Figure 1 illustrates the profile of a typical explosion crater on the ground surface, whose dimensions are measured with respect to the original ground level [4]. A true crater is defined as the boundary between the loose or broken fallback material and the underlying material that has been crushed and fractured but has not undergone significant vertical displacement. A resulting lip is typically formed around the crater, which is composed of uplifted and deformed rock or soil that has been ejected and thrown out of the crater. The primary parameters that influence the size and shape of the explosion crater are the weight of the explosives, the depth of the explosion, the formation method, and the geological structure of the ground.

Explosion craters have been widely studied through field experiments, numerical simulations, and theoretical analyses. Explosion craters were produced in some desert alluvium with a range of energy releases from 256 to $1,000,000$ pounds of TNT equivalent in a study conducted by Murphey et al. [5], which focused on craters generated by buried explosives. Further, the optimum depth of the burst for a constant explosive weight was also obtained. Another study [6] reported the results of experiments on craters generated by chemical and nuclear surface explosions with different TNT equivalents (1-5,000 tons) on different types of soil. The formulae for calculating the diameter, volume, and depth of craters based on the charge amount were also determined, and the relationships between these formulae were 


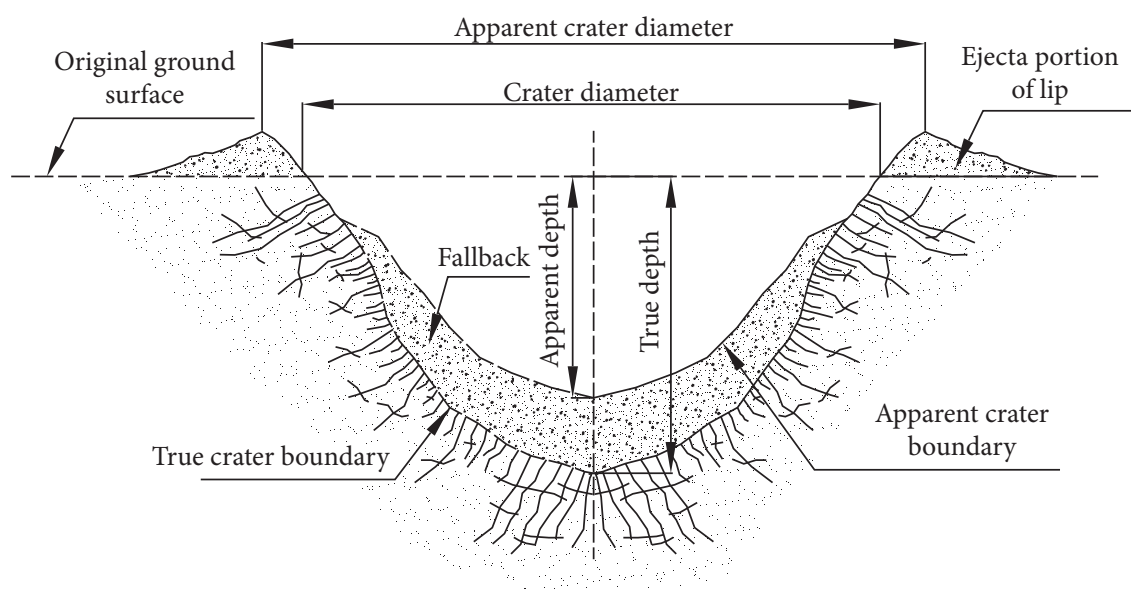

Figure 1: Typical profile of an explosion crater [4].

discussed. Furthermore, experimental studies of craters produced by explosive loads located on, above, or below the soil surface were presented in [7]. From the 1950s to the 1960s, data related to explosion craters were collected for use in nuclear excavation projects [8]. These data were obtained from more than 10 crater programs using chemical explosives and seven nuclear crater detonations. The types of experimental media ranged from marine muck to hard, dry basalt and desert alluvium and led to some significant conclusions relevant to nuclear excavation. For example, Ohkubo et al. [9] investigated the effectiveness of carbon or aramid fiber sheet reinforcement on the blast-resistant performance of concrete plates. They found that aramid fiber sheets exhibited a better reinforcement effect than the carbon fiber sheet and that reinforcement with two fiber sheets enabled the concrete plate to remain intact. As the number of fiber sheets increased, the diameter, depth of the craters, and the width of the damage to the interface decreased rapidly. This shows that the smaller the crater, the less the damage to the backside.

Numerical studies have provided another way to study the relationship between the weight and location of the explosive and the diameter of the generated crater $[10,11]$. In [12], the authors used a fully coupled Euler-Lagrange interaction to correctly model the pressures and soil deformation created simultaneously by the explosion in a developed 2D-axisymmetric model. In [13], the crater dimensions were derived from a 2D-numerical-physical model during the gas acceleration phase of excavation for high-explosive sources in alluvium. The results were found to closely match those obtained from field tests and centrifuge model tests. Bull et al. [14] used numerical methods to study the effects produced by a chemical explosion in the support material under a runway. The finite element (FE) model was used to calculate the displacements and stresses, which were then used to determine the requirements of crater repair to achieve a specified life expectancy of the crater. Wang et al. [15] conducted a numerical analysis of crater blasting in steel fiber-reinforced concrete. The adopted model and highpressure equation of state (EOS) effectively captured the main characteristics and failure process of the concrete under blast loading, indicating that the volume fraction of fibers had a significant influence on the size of the explosion craters.

Regarding theoretical research on explosion craters, Baker et al. [16] proposed a functional relationship for craters based on six parameters through dimensional analysis and many empirical observations. However, only five parameters were used to characterize the radius of a crater created by the detonation of explosives according to Westine [17], whose theory could predict crater dimensions for known charge weight, buried depth, and soil properties. Pokroyski et al. $[18,19]$ obtained a theoretical equation using theoretical deduction and hypothesis. Moreover, the proper scaling of crater dimensions resulting from buried explosives was investigated in [20]. Four different scaling rules were derived from dimensional analyses; however, no clear answer to the scaling question was provided. Hill et al. [21] used two methods of scaling, which were consistent with the Baldwin crater relationship but preserved different features of cube-root scaling, resulting in scaling relationships for the depth of a high-energy explosion crater that are not simple power laws. Their methods predicted scaling results for terrestrial meteoritic craters that lie within the range of those predicted by other studies.

A geotechnical centrifuge $[22,23]$ is a valuable experimental tool for studying impact and explosion craters. In 1976, Schmidt was the first to report explosion crater data generated by scale tests in the centrifuge at Boeing Company, Seattle, Washington, using small chemical explosives and small projectiles at high velocities. The work revolutionized the science of crater prediction at nuclear explosive levels or crater predictions related to planetary impacts of large bodies. Other research has used centrifuge experimental techniques in the laboratory to simulate shallowburied full-scale nuclear crater events [24-27]. Furthermore, Hansen et al. [28] used centrifuge modeling and novel measurement methodologies to augment the current literature by quantifying buried, explosive-induced, high-rate soil ejecta kinematics in conjunction with crater morphology. In their research, the soil stratum configuration 
consisted of dry Colorado Mason sand with a mass gravity of $2.62 \mathrm{~g} / \mathrm{cm}^{3}$. The experimental results confirmed that centrifuge modeling enables small gram-sized charges to simulate the typical blast energy of a full-scale field test. These new measurement methodologies have many potential applications.

Nevertheless, literature referring to craters induced by the surface explosion of large weight explosives remains limited. Moreover, most crater studies refer to rock and soil, but there is little research on craters in the Gobi Desert. In this study, four field contact explosion tests were conducted on the Gobi Desert surface using large amounts of explosives, i.e., 1 ton, 3 tons, and 10 tons of TNT. A fine-mesh numerical model was developed and validated on the AUTODYN software platform. Based on this model, a detailed parametric analysis was performed, including the density of sand and gravel. Additionally, the initiation detonation method, shear modulus, and failure criteria were analyzed and discussed. Finally, a theoretical study of explosion craters was conducted, deriving the energy conversion coefficient and the corresponding equations to predict the crater dimensions.

\section{Experimental Procedures}

2.1. Test Site and Preparation of TNT Explosives. The tests were conducted in the Gobi Desert, located in the Inner Mongolia Province, China. The sediment was alluvial-diluvial fine-grained sand with dense black-gray and reddishbrown gravel, and the gravel coverage was between $40 \%$ and $60 \%$ [29]. Gravel sizes are heterogeneous; most are greater than $2 \times 10^{-3} \mathrm{~m}$, with the majority between $0.016 \mathrm{~m}$ and $0.064 \mathrm{~m}$, while a few are greater than $0.256 \mathrm{~m}$. Similarly, sand sizes range from $6.25 \times 10^{-5}$ to $2 \times 10^{-3} \mathrm{~m}$, with the majority between $2.5 \times 10^{-4} \mathrm{~m}$ and $1 \times 10^{-3} \mathrm{~m}$.

Figures 2(a) and 2(b) show the geological features of the Gobi Desert. The gravel is agate stone, predominantly composed of silica, and has the same composition as glass and quartz. The densities of the gravel and sand were $2.65 \mathrm{~g} / \mathrm{cm}^{3}$ and $1.67-2.0 \mathrm{~g} / \mathrm{cm}^{3}$ [29], respectively. The minimum mixture density of the sand and gravel was $2.26 \mathrm{~g} / \mathrm{cm}^{3}$, while the gravel coverage was $40 \%$. The density of the sand is $1.67 \mathrm{~g} / \mathrm{cm}^{3}$, and the maximum mixture density of the sand and gravel was $2.39 \mathrm{~g} / \mathrm{cm}^{3}$, while the gravel coverage was $60 \%$. The density of the sand was $2.0 \mathrm{~g} / \mathrm{cm}^{3}$. Consequently, the mixture density of the sand and gravel lay between $2.26 \mathrm{~g} / \mathrm{cm}^{3}$ and $2.39 \mathrm{~g} / \mathrm{cm}^{3}$. The test site was a low flat open area. Figure 2(c) shows the explosive used in test 1 in the test area. The explosive consisted of an initiating explosive column, a cast TNT cylinder, and bulk TNT powder packed in nylon bags. Each bag of bulk TNT powder weighed $50 \mathrm{~kg}$. Figure 2(d) shows the cast TNT cylinder with a size of $\varphi 0.35 \mathrm{~m} \times$ $0.325 \mathrm{~m}$. Charge weights of 1 ton and 3 tons of TNT explosives had volumes of $1.96 \mathrm{~m} \times 2.0 \mathrm{~m} \times 1.2 \mathrm{~m}$ and $3.1 \mathrm{~m} \times 3.14 \mathrm{~m} \times 1.45 \mathrm{~m}$, respectively. The two weights of 10 tons of TNT explosives had volumes of $4.8 \mathrm{~m} \times 5.0 \mathrm{~m} \times 1.96 \mathrm{~m}$ and $4.9 \mathrm{~m} \times 5.06 \mathrm{~m} \times 2.0 \mathrm{~m}$ for test 3 and test 4 , respectively.
2.2. Field Explosion Test. Four explosion tests were conducted on the Gobi ground surface with TNT charge weights of 1 ton, 3 tons, and 10 tons (test conducted twice) of TNT explosives, as listed in Table 1. Each detonation consisted of two stages of initiation. In the first step, two detonators were used to initiate the initial explosive column, which was used to detonate the cast TNT cylinder. In the second step, the cast TNT cylinder was used to detonate the bulk TNT, which was packed in nylon bags. Figure 3 shows a cross-sectional view of the arrangement of the explosives. Figure 4 presents the resulting craters observed after the in situ blast tests.

As shown in Figure 4, the corresponding resulting crater sizes are measured using the apparent crater diameter, $D$, and the crater depth, $H$, according to the definition in Figure 1. Two measurements were performed for each parameter, i.e., $D_{1}$ and $D_{2}$, and $H_{1}$ and $H_{2}$, where $D_{1}$ corresponds to $H_{1}$, and $D_{2}$ corresponds to $H_{2}$. The diameters $D_{1}$ and $D_{2}$ were perpendicular to each other. In Figure 4, the mean $D$ value is the average of $D_{1}$ and $D_{2}$, and the mean $H$ value is the average of $H_{1}$ and $H_{2}$.

As shown in Figure 4, the shapes of the craters were roughly those of circular funnels, with fallen gravel and sand on the surface of the craters. There were no obvious cracks in the ground around the crater of test 1 (Figure 4(a)). Conversely, in test 2, there were many obvious cracks in the ejecta of the crater. Additionally, the width of the cracks was approximately $0.03-0.04 \mathrm{~m}$, and there was a circular uplift in the crater with a diameter of $7.00 \mathrm{~m}$ (Figure 4(b)). In test 3, the width of the cracks was approximately $0.04-0.06 \mathrm{~m}$, and the diameter of uplift is approximately $9.22 \mathrm{~m}$ (Figure 4(c)). However, we only measured and recorded the crater data in test 4 and did not take any pictures for the crater in test 4 .

Table 1 shows the characteristic data of the craters generated by explosions on the ground surface. Based on Table 1, it can be inferred that the crater diameter of the 3ton test is $121 \%$ larger than that of the 1-ton test. Similarly, the crater diameter of the 10 -ton test is $41.5 \%$ larger than that of the 3-ton test. It can also be deduced that the diameter of the crater is not linearly related to the mass of the explosive In Table $1, n$ is the blasting action index, which is defined as $n=(D / 2) / H$. The blasting index shows the change in the crater size and it determines the difference between the soil failure scope and the throwing action. The blasting index $n$ is found to be between 2.21 and 3.33 .

\section{Numerical Analysis}

The modeling software AUTODYN has been developed specifically for analyzing nonlinear dynamic events, such as the impacts and blast loading of structures and components. The program offers users a variety of numerical techniques for problem-solving. These include Lagrange, Shell, Euler, ALE, and SPH solvers [30]. In this study, the Gobi Desert surface consisted of sand and gravel. The Lagrange solver is suitable for modeling sand and gravel and was used for their modeling (the sand and gravel of the Gobi Desert were regarded as similar materials to sand in this simulation). The Euler solver was used to model the air and TNT. 


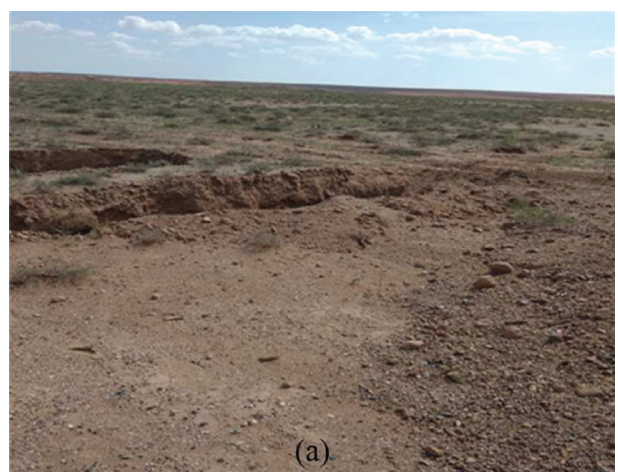

(a)

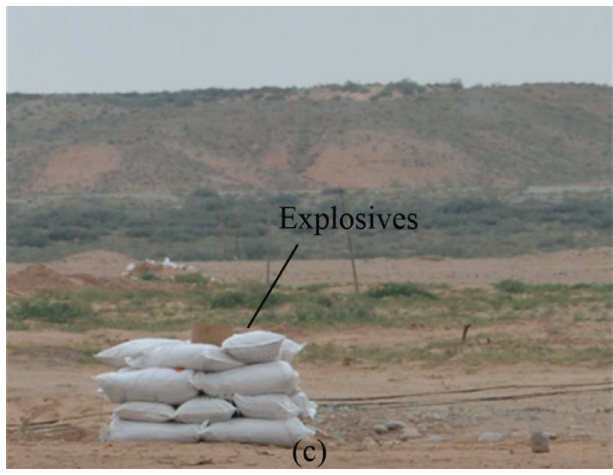

(c)

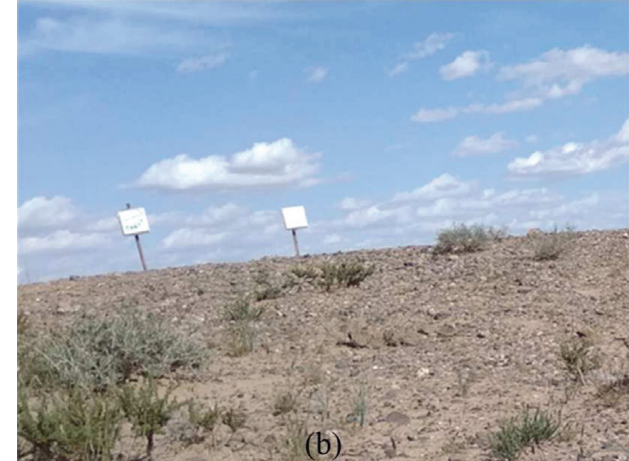

(b)

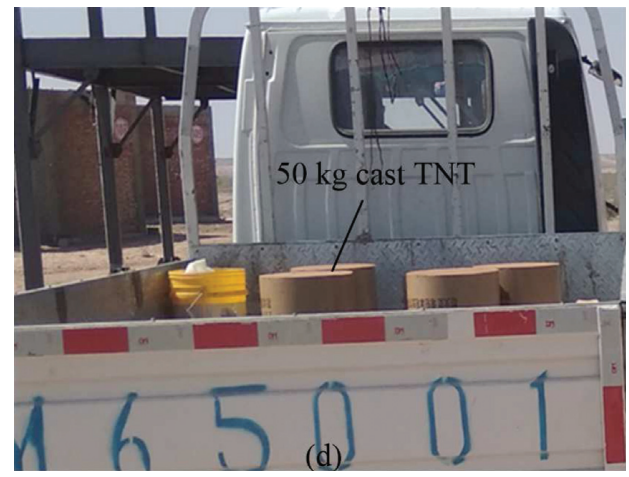

(d)

FIgURe 2: Photographs of the test area $(a, b)$. The explosives and cast TNT used on the test site (c, d).

TABLE 1: Experimental crater dimensions.

\begin{tabular}{lccccccrr}
\hline Test $i$ & $W($ ton $)$ & $D_{1}(\mathrm{~m})$ & $D_{2}(\mathrm{~m})$ & Mean $D(\mathrm{~m})$ & $H_{1}(\mathrm{~m})$ & $H_{2}(\mathrm{~m})$ & Mean $H(\mathrm{~m})$ & $n_{\mathrm{i}}$ \\
\hline 1 & 1 & 4.620 & 4.420 & 4.520 & 0.910 & 0.980 & 0.945 & 2.39 \\
2 & 3 & 9.600 & 1.040 & 10.000 & 1.540 & 1.460 & 1.500 & 3.33 \\
3 & 10 & 13.820 & 13.660 & 13.740 & 3.040 & 3.160 & 3.100 & 2.21 \\
4 & 10 & 14.610 & 14.490 & 14.550 & 2.470 & 2.330 & 2.400 & 3.03 \\
\hline
\end{tabular}

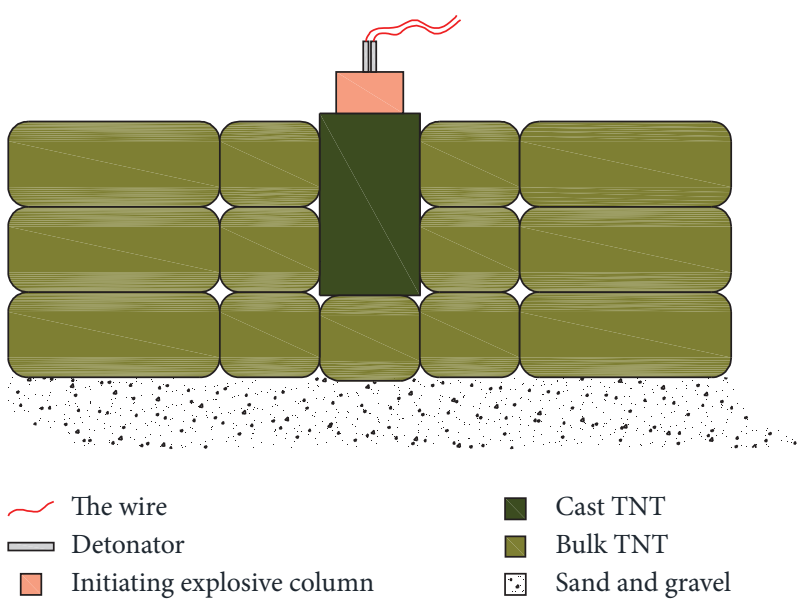

FIGURE 3: Cross section of explosive arrangement on the ground. 


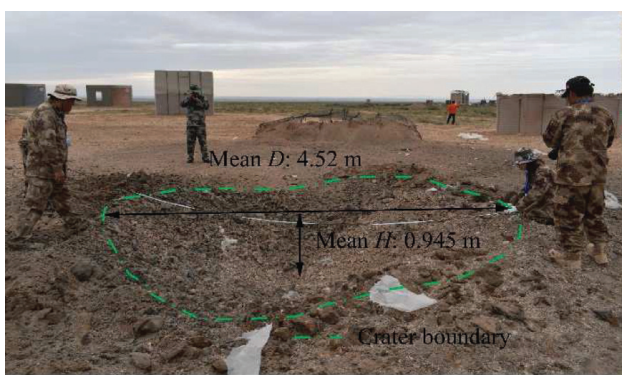

(a)

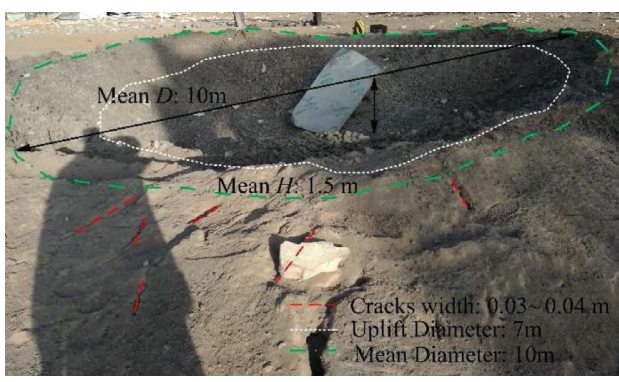

(b)

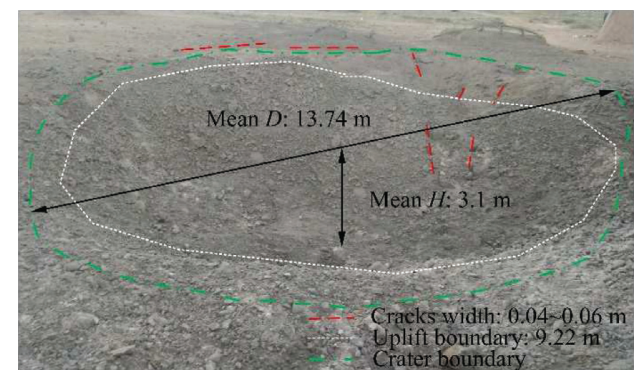

(c)

Figure 4: Craters generated by ground explosions of (a) 1 ton, (b) 3 tons, and (c) 10 tons of explosives.

3.1. FE Model. A 2D-axisymmetric model was developed for the cratering caused by contact explosions on the Gobi Desert surface, which consisted of air and TNT, plus sand and gravel. The TNT explosive was surrounded by air, which was directly above the sand and gravel. The geometrical model and boundary conditions of the FE model are presented in Figure 5.

In this study, the flow-out boundary was defined in the Euler part, which allows transmission/flow-out of the computational domain. A velocity boundary was used in the Lagrange part, which restricts movement along the bottom surface and outer side of the Lagrange part. An automatic Euler-Lagrange coupling was used to model the fluid-solid interaction. This coupling is polygon-free; it allows large deformations of the fluid phase and uses the solids to provide boundaries for interaction with the fluid. When the fluid flows to the solid boundary, it induces stress fields on the solid.

Three different square meshes, with the sizes of 0.03 , $0.04 \mathrm{~m}$, and $0.05 \mathrm{~m}$, were applied to simulate the process of the crater. With the decrease in the mesh size from $0.05 \mathrm{~m}$ to $0.03 \mathrm{~m}$, the diameter of the crater converges to a value of $4.480 \mathrm{~m}$ using a square shape element of size $0.04 \mathrm{~m}$ by 1 -ton TNT test, and the error between the simulation value and test value was $-0.8 \%$. Thus, a $0.04 \mathrm{~m} \times 0.04 \mathrm{~m}$ cell was used to simulate the crater formation. In the Euler part of the model, which had a grid size of $0.04 \mathrm{~m} \times 0.04 \mathrm{~m}$ and comprised air and TNT, the size of the geometrical model was $16.00 \mathrm{~m} \times 10.00 \mathrm{~m}$, with a total of 100,651 nodes and 100,000 elements. In the Lagrange part, which had a grid size of $0.04 \times 0.04 \mathrm{~m}$ and comprised sand and gravel, the size of the geometrical model was $32.00 \mathrm{~m} \times 4.00 \mathrm{~m}$, with a total of 80,901 nodes and 80,000 elements.
3.2. Material Model and Parameters. The air, TNT, and the mixture of sand and gravel were determined as the research objects to simulate the explosion craters. In particular, the mixture of sand and gravel is a porous material like soil and sand. Therefore, the most suitable material model should be selected to simulate the generation of craters. The various material parameters are presented in the following subsections.

3.2.1. Air. Air follows an ideal gas state equation. One of the simplest forms of the EOS is that of an ideal polytrophic gas, which is used in many applications involving the motion of gases. It was derived from the laws of Boyle and Gay-Lussac [31] and is expressed as

$$
p=(\gamma-1) \rho e,
$$

where $p$ is the hydrostatic pressure, $\rho$ is the density, $e$ is the specific internal energy, and $\gamma$ is the adiabatic exponent, which is assumed to be constant. The values of the constants used for the air are listed in Table 2.

3.2.2. TNT. The state equation for the TNT is the Jones-Wilkins-Lee (JWL) EOS [32], which describes the detonation product expansion down to a pressure of $100 \mathrm{MPa}$ for high-energy explosive materials based on the following equation:

$$
P=A\left(1-\frac{\omega \eta}{R_{1}}\right) e^{-R_{1} / \eta}+B\left(1-\frac{\omega \eta}{R_{2}}\right) e^{-R_{2} / \eta}+\omega \rho e,
$$

where $\rho_{0}$ is the reference density, $\rho$ is the density, and $\eta=\rho_{0} / \rho$. The constants $A, B, R_{1}, R_{2}$, and $\omega$ have previously been determined from previous explosion experiments. The 


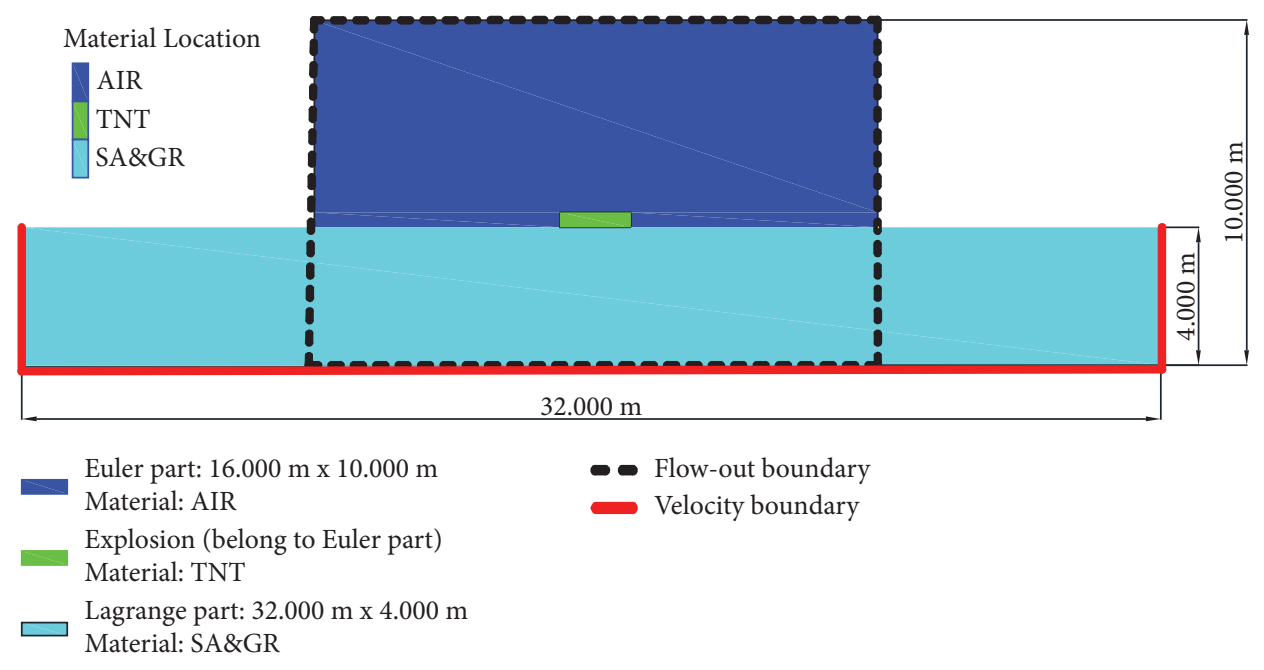

Figure 5: Geometrical model and boundary conditions.

TABLE 2: Material parameters of air.

\begin{tabular}{lc}
\hline Equation of state & Ideal gas \\
\hline Reference density & $\rho_{0}=1.225 \times 10^{-3} \mathrm{~g} / \mathrm{cm}^{3}$ \\
Gamma & $\gamma=1.4$ \\
Internal energy & $e_{0}=2.0664 \times 10^{5} \mathrm{~J}$ \\
Reference temperature & $T_{0}=288.2 \mathrm{~K}$ \\
Specific heat & $c_{\mathrm{v}}=717.6 \mathrm{~J} / \mathrm{kgK}$ \\
\hline
\end{tabular}

values determined for the TNT explosive are presented in Table 3.

3.2.3. Sand and Gravel. In AUTODYN, a polynomial EOS serves as the general form of the Mie-Gruneisen form of the EOS and it has different analytic forms for states of compression and tension. This EOS is as follows.

$\mu>0$ (compression):

$$
p=A_{1} \mu+A_{2} \mu^{2}+A_{3} \mu^{3}+\left(B_{0}+B_{1} \mu\right) p_{0} e .
$$

$\mu<0$ (tension):

$$
p=T_{1} \mu+T_{2} \mu^{2}+B_{0} p_{0} e
$$

where $\mu=\rho / \rho_{0}-1, \rho_{0}$ is zero pressure density of the material, $e$ is the internal energy per unit mass, and $A_{1}, A_{2}, A_{3}$, $B_{0}, B_{1}, T_{1}$, and $T_{2}$ are material constants.

The strength model used for the mixture of sand and gravel is the Johnson-Holmquist Strength [33], which is described as a smoothly varying function of intact strength, fractured strength, strain rate, and damage via a dimensionless analytic function as described in the following.

Intact surface is

$$
\sigma_{i}^{*}=A\left(P^{*}+T^{*}\right)^{n}\left(1+\operatorname{CIn\varepsilon }_{P}^{*}\right) .
$$

Damage is

$$
\sigma_{S}^{*}=\sigma_{i}^{*}-S\left(\sigma_{i}^{*}-\sigma_{F}^{*}\right)
$$

Fractured is
TABLE 3: Material parameters of TNT explosives.

\begin{tabular}{lc}
\hline Equation of state & JWL \\
\hline Reference density & $\rho=1.63 \mathrm{~g} / \mathrm{cm}^{3}$ \\
Parameter $A$ & $A=3.7337 \times 10^{8} \mathrm{Kpa}$ \\
Parameter $B$ & $B=3.7410 \times 10^{6} \mathrm{Kpa}$ \\
Parameter $R 1$ & $R_{1}=4.15$ \\
Parameter $R 2$ & $R_{2}=0.9$ \\
Parameter $\omega$ & $\omega=0.35$ \\
C-J detonation velocity & $D=6.93 \times 10^{3} \mathrm{~m} / \mathrm{s}$ \\
C-J energy/unit volume & $E=6.0 \times 10^{6} \mathrm{KJ} / \mathrm{m}^{3}$ \\
C-J pressure & $P=2.1 \times 10^{7} \mathrm{KPa}$ \\
\hline
\end{tabular}

$$
\sigma_{F}^{*}=\operatorname{MIN}\left[B\left(P^{*}\right)^{m}\left(1+C \operatorname{In} \varepsilon_{P}^{*}\right), \sigma_{F}^{\operatorname{Max}}\right],
$$

where $P^{*}=P / P_{\mathrm{HEL}}, P$ is the actual pressure and $P_{\mathrm{HEL}}$ is the pressure at the Hugoniot elastic limit, $T^{*}=T / P_{\mathrm{HEL}}$, and $T$ is the maximum tensile hydrostatic pressure the material can withstand. The effective plastic strain rate $\varepsilon_{P}^{*}$ is normalized by a reference strain rate of $1.0 /$ second. $\sigma_{D}^{*}$ is the normalized intact equivalent stress, $\sigma_{F}^{*}$ is the normalized fracture stress, and $S$ is the damage $(0 \leq S \leq 1.0))$. The normalized equivalent stresses $\left(\sigma_{S}^{*}, \sigma_{i}^{*}, \sigma_{F}^{*}\right)$ have the general form $\sigma_{S}^{*}=\sigma_{S} / \sigma_{\mathrm{HEL}}$, where $\sigma_{S}$ is the actual equivalent stress and $\sigma_{H E L}$ is the equivalent stress at the Hugoniot elastic limit, and $A, B, C, m$, and $n$ are constants.

The damage model is expressed as

$$
\begin{aligned}
S & =\sum \frac{\Delta \varepsilon^{P}}{\varepsilon_{f}^{P}}, \\
\varepsilon_{f}^{P} & =S_{1}\left(P^{*}+T^{*}\right)^{S_{2}},
\end{aligned}
$$

where $\Delta \varepsilon^{P}$ is the plastic strain during a cycle of integration, and $\varepsilon_{f}^{P}$ is the plastic strain to fracture under constant pressure, $P$. The parameters $S_{1}$ and $S_{2}$ are constants. Figures 6(a) and 6(b) show the strength and damage models of the sand and gravel. The values used for the sand and gravel EOS are presented in Table 4. 


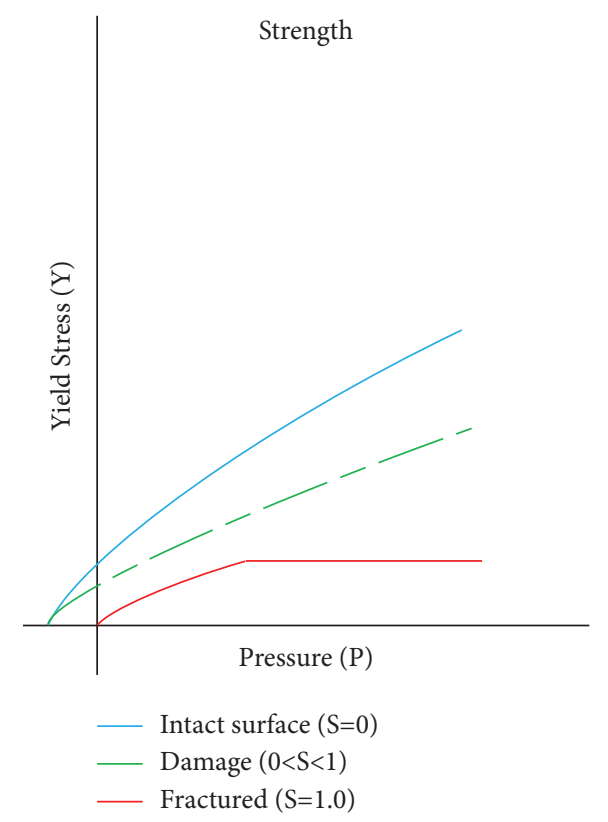

(a)

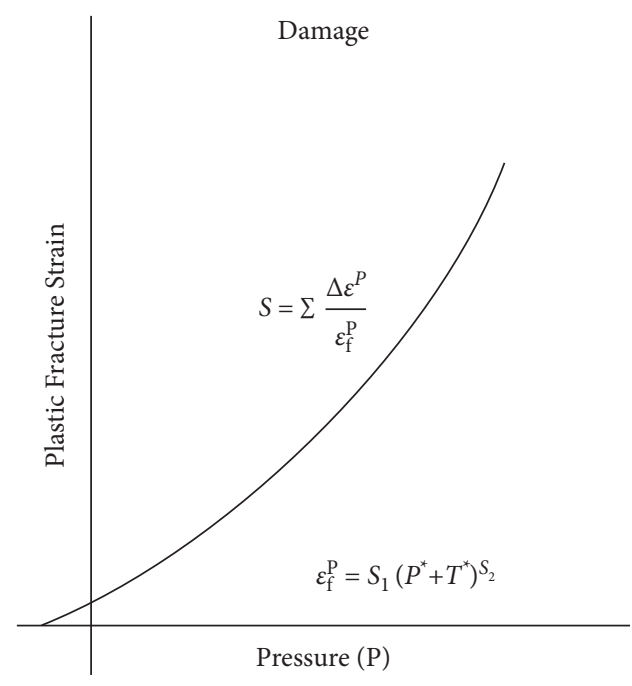

(b)

FIGURE 6: The strength and damage models of the sand and gravel.

TABLE 4: Values used for the sand and gravel EOS and the strength model.

\begin{tabular}{|c|c|c|c|}
\hline Equation of state & Polynomial EOS & & \\
\hline Reference density & $2.26 \mathrm{~g} / \mathrm{cm}^{3}$ & & \\
\hline Parameter $A_{1}$ & $1.68928 \times 10^{7} \mathrm{kPa}$ & Parameter $A_{2}$ & $1.65 \times 10^{7} \mathrm{kPa}$ \\
\hline Parameter $A_{3}$ & $3.734 \times 10^{8} \mathrm{kPa}$ & Parameter $B_{0}$ & 0 \\
\hline Parameter $B_{1}$ & 0 & Parameter $T_{1}$ & $1.68928 \times 10^{7} \mathrm{kPa}$ \\
\hline Parameter $T_{2}$ & 0 & Reference temperature & 0 \\
\hline Specific heat & 0 & Thermal conductivity & 0 \\
\hline Strength model & Johnson-Holmquist strength & & \\
\hline Shear modulus & $7.769 \times 10^{6} \mathrm{kPa}$ & Model type & Continuous \\
\hline Hugoniot elastic limit & $1.950 \times 10^{5} \mathrm{kPa}$ & Intact strength constant $A$ & 0.90 \\
\hline Intact strength exponent $n$ & 0.75 & Strain rate constant $C$ & 0.003 \\
\hline Fractured strength $B$ & 0.31 & Fractured strength $m$ & 0.39 \\
\hline Max. fracture strength ratio & 0.50 & & \\
\hline Failure & Johnson-Holmquist & & \\
\hline Hydrotensile limit & $-100 \mathrm{kPa}$ & Model type & Continuous \\
\hline Damage constant, $S_{1}$ & 0.20 & Damage constant, $S_{2}$ & 0.50 \\
\hline Bulking constant, beta & 1.00 & Damage type & Gradual \\
\hline Tensile failure & Hydro & & \\
\hline
\end{tabular}

The values used for the sand and gravel EOS are presented in Table 4.

3.3. Model Validation. Based on the size of the explosives, their shapes were regarded as that of a cylinder. The radius of the 1 ton, 3 tons, and 10 tons of TNT explosives was $0.99 \mathrm{~m}$, $1.560 \mathrm{~m}$, and $2.470 \mathrm{~m}$, respectively. As previously mentioned, the density of the TNT was $1.63 \mathrm{~g} / \mathrm{cm} 3$, and the heights of the 1 ton, 3 tons, and 10 tons of TNT explosives were $0.200 \mathrm{~m}, 0.240 \mathrm{~m}$, and $0.320 \mathrm{~m}$, respectively. It took approximately $12 \mathrm{~ms}$ for the crater generated by a 1-ton explosive to form, while the time for the craters generated by
3 tons and 10 tons of TNT to form was $33 \mathrm{~ms}$ and $40 \mathrm{~ms}$, respectively.

The known relationship between the bulk modulus and shear modulus is

$$
\frac{K}{G}=\frac{2(1+v)}{3(1-2 v)}
$$

where $K$ is the bulk modulus, $G$ is the shear modulus, and $v$ is Poisson's ratio of the material.

The shear modulus of the sand and gravel is $7.769 \times 10^{3} \mathrm{MPa}$, which can be determined using [34]. Poisson's ratio of sand and gravel ranges from 0.15 to 0.35 , 
which can be determined based on [35]. The selected Poisson's ratio of sand and gravel is 0.3 ; generally, sand and gravel are dense sediments. The value of parameter $A_{1}$ for the sand and gravel can be calculated as $1.68928 \times 10^{7} \mathrm{KPa}$ by inserting Poisson's ratio and shear modulus values into equation (9). The values of the parameters $A_{2}$ and $A_{3}$ were taken from [34]. The value of $T_{1}$ was usually set to the material bulk modulus. The Hugoniot elastic limit of the sand and gravel was $1.95 \times 10^{2} \mathrm{MPa}$, which can be determined according to [36]. The reference value for the hydrotensile limit was set as $-100 \mathrm{KPa}$ according to [11], and it was discussed in more detail in Section 3.4. Constants of $A, B, C, m, n, D_{1}$, and $D_{2}$ refer to the values in the Johnson-Holmquist strength model, and they were modified. The parameters of the air and TNT were provided by the software. The calculated profiles of the crater induced by 1 ton, 3-ton, and 10-ton contact explosions on the Gobi Desert surface are presented in Figure 7 as a side view of the cross section. The corresponding detailed dimensions are compared with the test data in Table 5 .

It can be observed that the calculated diameters of the craters generated by 1 ton, 3 tons, and 10 tons of TNT are comparable to the test data. The absolute errors of the diameters are less than 9\%. Additionally, the error divergence of the depth was relatively large because the simulated crater depth is the true depth, whereas the testing value is actually the apparent depth. As expected, part of the gravel and sand would fall back into the crater after the detonation of the explosive, causing the apparent depth to be less than the true depth. The simulation results indicate that the developed FE model can accurately predict the cratering effects generated by the contact explosion of a large weight of explosives in the Gobi Desert.

3.4. Parametric Discussion. To find out the influences of the sand and gravel properties on the cratering effects, intensive numerical simulations were conducted by varying the density, initiation method, elastic failure, and yield strength properties. The mixture density of sand and gravel varied between the critical values of $2.26-2.39 \mathrm{~g} / \mathrm{cm}^{3}$ and was first employed to simulate the craters. The calculated results are presented in Table 6. For a density of $\rho_{1}$, the calculated crater diameter and depth are $D_{\rho_{1}}$ and $H_{\rho_{1}}$, respectively; for a density of $\rho_{2}$, the calculated crater diameter and depth are $D_{\rho_{1}}$ and $H_{\rho_{2}}$, respectively. The ratio $D_{\rho_{1}} / D_{\rho_{2}}$ ranges from 1.02 to 1.05 , whereas the ratio $H_{\rho_{1}} / H_{\rho_{2}}$ ranges from 1.02 to 1.04. The density had only a slight influence on the diameter or depth of the crater caused by an explosion of large charge weights. However, the mixture density of sand and gravel varies only in a limited range of $2.26 \mathrm{~g} / \mathrm{cm}^{3}-2.39 \mathrm{~g} / \mathrm{cm}^{3}$ with a low change rate of $6 \%$. Therefore, the dispersion degree of density can be ignored due to the large charge weight of the explosion. It should be noted that, for different media with large density dispersion, the influence of density should be considered.

Point detonation and line detonation were considered as the two initiation methods in the numerical simulation. The corresponding simulated results of point initiation are $D_{P}$ and $H_{P}$. For the line detonation, the results are $D_{L}$ and $H_{L}$. Figure 8 shows the two types of initiation modes. The position of point detonation is on the top of the charge. The starting position of the line initiation is also on the top of the charge, with a length of the charge height. The calculated results are presented in Table 7. It was found that the ratio $D_{P} / D_{L}$ in the different initiation modes ranged from 1.01 to 1.02 , whereas the ratio $H_{P} / H_{L}$ ranged from 0.98 to 1.02 . This indicated that the detonation method had only a slight effect on the crater size.

The influence of the shear modulus of the sand and gravel mixture was also considered. It varied from $7.769 \times 10^{3} \mathrm{MPa}$ to $1.000 \times 10^{4} \mathrm{MPa}$. The simulated crater diameter with a shear modulus of $7.769 \times 10^{3} \mathrm{MPa}$ was defined as the benchmark $D_{\mathrm{SM} 1}$, whereas $D_{\mathrm{SM} 2}$ described the simulated crater diameter with a shear modulus of $9.000 \times 10^{3} \mathrm{MPa}$, and $D_{\mathrm{SM} 3}$ described the simulated diameter with a shear modulus of $1.000 \times 10^{4} \mathrm{MPa}$. The results are listed in Table 8. It was found that the diameter ratio $D_{\mathrm{SM} 2} / D_{\mathrm{SM} 1}$ ranged from 0.81 to 0.88 and the diameter ratio $D_{\mathrm{SM} 3} / D_{\mathrm{SM} 1}$ ranged from 0.69 to 0.82 , which demonstrated that the influence of the shear modulus on the crater dimensions is significant.

The shear modulus influences the size of the crater significantly because parameter $A_{1}$ plays a key role in equation (3). When the shear modulus increases, the bulk modulus also increases. An increase in the bulk modulus will lead to an increase in $p$, which makes the material more difficult to compress and results in a decrease in the diameter of the crater.

Table 9 provides the simulated results considering the influence of the hydrotensile limit on the crater dimensions. The hydrotensile limit ranged from $-100 \mathrm{KPa}$ to $-1000 \mathrm{KPa}$ in the calculation. The simulated results for the crater diameter were designated as $D_{\mathrm{HT} 1}, D_{\mathrm{HT} 2}$, and $D_{\mathrm{HT} 3}$, with $D_{\mathrm{HT} 1}$ being considered the benchmark. However, it was found that the ratio $D_{\mathrm{HT} 2} / D_{\mathrm{HT} 1}$ ranged from 0.96 to 0.99 , whereas the ratio $D_{\mathrm{HT} 3} / D_{\mathrm{HT} 1}$ ranged from 0.93 to 0.97 , which demonstrates that the hydrotensile limit has a slight effect on the crater size.

Putting it concisely, the dispersion degree of the density, initiation method, and hydrotensile limit have little influence on the dimensions of the crater induced by the contact explosion of large charge weights, while the shear modulus has a significant influence on the dimensions of the crater.

\section{Theoretical Analysis}

4.1. Theoretical Derivation of the Formulae for Crater Diameter and Depth. A statistical study [37] of approximately 200 accidental surface explosions of large weight explosives provided an equation for the crater diameter, $D(\mathrm{~m})$, in terms of explosion yield, TNT equivalent, and $W(\mathrm{~kg})$ :

$$
D=0.8 W^{1 / 3} .
$$

The substantial variability in the crater formation was revealed by the standard deviations of approximately onethird of the values given by (10); the calculated values differ 


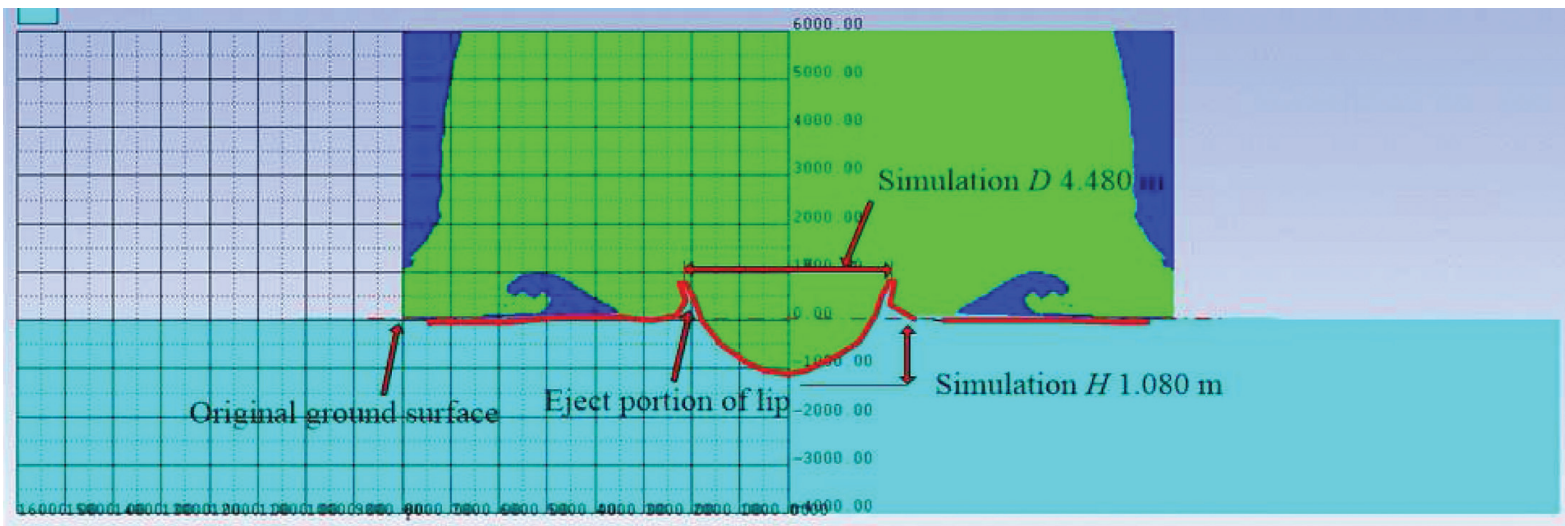

crater-1t-p2-26-sheat-modulus $7-769 \mathrm{e} 6$-hydro-tensile-limit-100kpa

Cycle 12628

Time 1.200E+01 ms

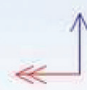

Units mm, mg, ms

Axial symmetry

(a)

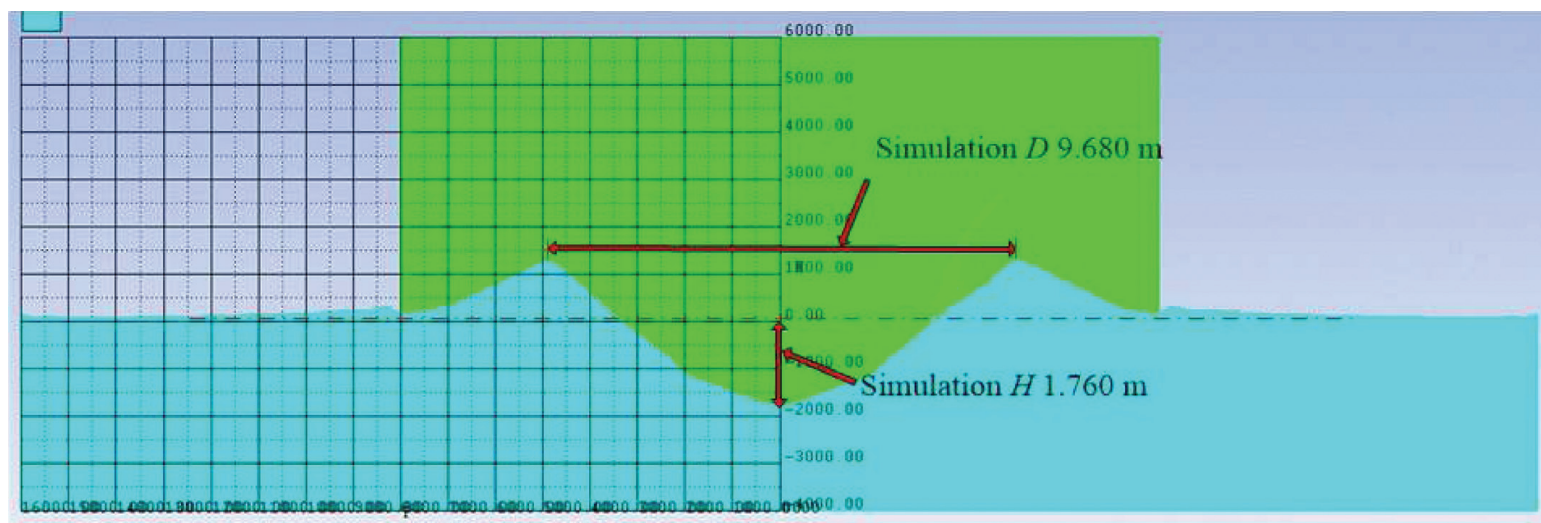

crater-3i-p2-26-shear-modulus $7-769$ e6-hydro-tensile-limit-100kpa

Cycle 56068

Time $3.300 \mathrm{E}+01 \mathrm{~ms}$

Units mm, mg, ms

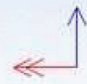

Axial symmetry

(b)

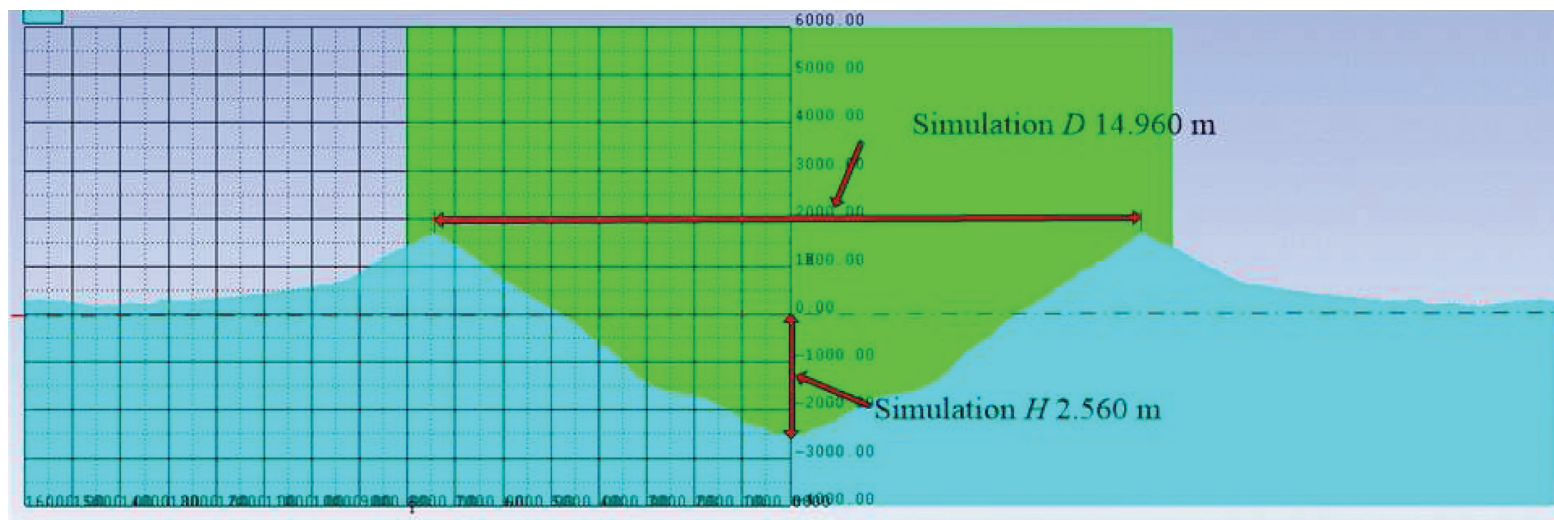

crater-10t-p2-26-shear-modulus $7-769 \mathrm{e6}-\mathrm{hy}$ dro-tensile-limit- $100 \mathrm{kpa}$

Cycle 70459

Time $40000 \mathrm{E}+01 \mathrm{~ms}$

Units $\mathrm{mm}, \mathrm{mg}$. $\mathrm{ms}$

Axial symmetry

(c)

Figure 7: Profiles of the crater generated by (a) 1 ton, (b) 3 tons, and (c) 10 tons of explosives. 
TABLE 5: Simulation results for the four test craters.

\begin{tabular}{lccccccc}
\hline Test $i$ & $W($ ton $)$ & Test $D(\mathrm{~m})$ & Test $H(\mathrm{~m})$ & Simulation $D(\mathrm{~m})$ & Simulation $H(\mathrm{~m})$ & Diameter deviation & Depth deviation \\
\hline 1 & 1 & 4.520 & 0.945 & 4.480 & 1.080 & $-0.8 \%$ & $14.3 \%$ \\
2 & 3 & 10.000 & 1.500 & 9.680 & 1.760 & $-3.2 \%$ & $-8.9 \%$ \\
3 & 10 & 13.740 & 3.100 & 14.960 & 2.560 & $-17.4 \%$ \\
4 & 10 & 14.550 & 2.400 & & & $2.8 \%$ & $6.7 \%$ \\
\hline
\end{tabular}

TABLe 6: Crater dimensions according to the sand and gravel density.

\begin{tabular}{|c|c|c|c|c|c|c|}
\hline$W$ (ton) & $D_{\rho_{1}}(\mathrm{~m})$ & $H_{\rho_{1}}(\mathrm{~m})$ & $D_{\rho_{2}}(\mathrm{~m})$ & $H_{\rho_{2}}(\mathrm{~m})$ & $D_{\rho_{1}} / D_{\rho_{2}}$ & $H_{\rho_{1}} / H_{\rho_{2}}$ \\
\hline 1 & 4.480 & 1.080 & 4.320 & 1.040 & 1.04 & 1.04 \\
\hline 3 & 9.680 & 1.760 & 9.200 & 1.720 & 1.05 & 1.02 \\
\hline 10 & 14.960 & 2.560 & 14.680 & 2.480 & 1.02 & 1.03 \\
\hline
\end{tabular}

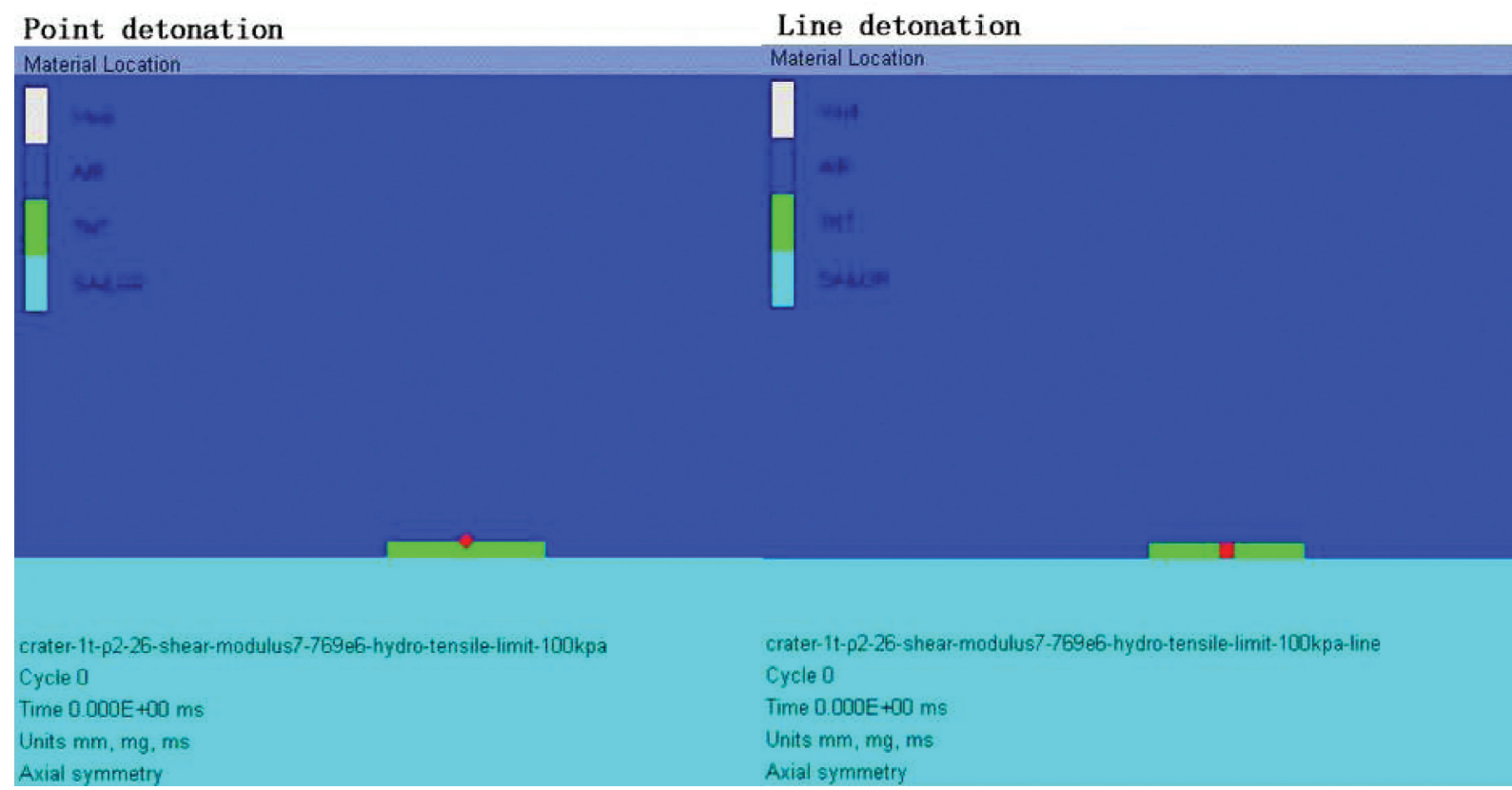

FIgURE 8: Two types of initiation modes.

TABLE 7: Crater dimensions according to the initiation detonation method.

\begin{tabular}{|c|c|c|c|c|c|c|}
\hline$W$ (ton) & $D_{\mathrm{P}}(\mathrm{m})$ & $H_{\mathrm{P}}(\mathrm{m})$ & $D_{\mathrm{L}}(\mathrm{m})$ & $H_{\mathrm{L}}(\mathrm{m})$ & $D_{\mathrm{P}} / D_{\mathrm{L}}$ & $H_{\mathrm{P}} / H_{\mathrm{L}}$ \\
\hline 1 & 4,480 & 1.080 & 4.400 & 1.080 & 1.02 & 1.00 \\
\hline 3 & 9,680 & 1.760 & 9.520 & 1.800 & 1.02 & 0.98 \\
\hline 10 & 14,960 & 2.560 & 14.880 & 2.520 & 1.01 & 1.02 \\
\hline
\end{tabular}

significantly from the test results. This is because only a part of the energy of the explosion was involved in creating the crater, which was affected by other factors, such as the soil properties and buried depth, while a constant coefficient of 0.8 would introduce significant error. The equation is apparently not suitable for explosions on the Gobi Desert surface.
Pokroyski and Tsernigovskii proposed a set of predicting formulae for buried explosions [18, 19], which were also proved to be effective. These equations can be derived from the lip conditions of the crater; the element must be thrown to the edge of the crater with sufficient velocity to overcome the friction due to contact with the pit wall and reach of the ground level. 
TABLE 8: Crater dimensions according to the shear modulus.

\begin{tabular}{|c|c|c|c|c|}
\hline$W$ (ton) & Shear modulus (MPa) & Numerical results $D_{\mathrm{SM}}(\mathrm{m})$ & $D_{\mathrm{SM} 2} / D_{\mathrm{SM} 1}$ & $D_{\mathrm{SM} 3} / D_{\mathrm{SM} 1}$ \\
\hline \multirow{4}{*}{1} & $7.769 \times 10^{3}$ & 4.480 & \multirow{4}{*}{0.87} & \multirow{4}{*}{0.82} \\
\hline & $9.000 \times 10^{3}$ & 3.840 & & \\
\hline & $1.000 \times 10^{4}$ & 3.680 & & \\
\hline & $7.769 \times 10^{3}$ & 9.680 & & \\
\hline \multirow[t]{2}{*}{3} & $9.000 \times 10^{3}$ & 7.840 & \multirow[t]{2}{*}{0.81} & \multirow[t]{2}{*}{0.69} \\
\hline & $1.000 \times 10^{4}$ & 6.680 & & \\
\hline \multirow[t]{2}{*}{10} & $9.000 \times 10^{3}$ & 13.200 & \multirow[t]{2}{*}{0.88} & \multirow[t]{2}{*}{0.81} \\
\hline & $1.000 \times 10^{4}$ & 12.080 & & \\
\hline
\end{tabular}

TABle 9: Crater dimensions according to the hydrotensile limit.

\begin{tabular}{lccccc}
\hline $\begin{array}{l}W \\
(\text { ton})\end{array}$ & $\begin{array}{c}D_{\mathrm{HT} 1} \\
(\mathrm{~m})\end{array}$ & $\begin{array}{c}D_{\mathrm{HT} 2} \\
(\mathrm{~m})\end{array}$ & $\begin{array}{c}D_{\mathrm{HT} 3} \\
(\mathrm{~m})\end{array}$ & $D_{\mathrm{HT} 2} / D_{\mathrm{HT} 1}$ & $D_{\mathrm{HT} 3} / D_{\mathrm{HT} 1}$ \\
\hline 1 & 4.480 & 4.320 & 4.160 & 0.96 & 0.93 \\
3 & 9.680 & 9.360 & 9.040 & 0.97 & 0.93 \\
10 & 14.960 & 14.880 & 14.560 & 0.99 & 0.97 \\
\hline
\end{tabular}

Therefore, as described in Figure 9, the first equation can be obtained as

$$
u_{\varphi 1} \cos \varphi=(2 g h)^{1 / 2},
$$

where $u_{\varphi}$ denotes the velocity of a debris element, $h$ is the depth of the soil element, $\varphi$ is the angle between the velocity vector of the element and the plumb line, $g$ is the acceleration due to gravity, and $u_{\varphi 1}$ and $u_{\varphi 2}$ are the two components of $u_{\varphi} ; u_{\varphi 1}=\cos \varphi \times u_{\varphi} ; u_{\varphi 2}=\sin \varphi \times u_{\varphi}$ (see in Figure 9). It is assumed that the kinetic energy of this debris element is equal to the work done by friction; thus, we obtain

$$
\frac{1}{2} m u_{\varphi 2}^{2} \cos ^{2} \varphi=f m g h .
$$

The second equation is

$$
\begin{aligned}
u_{\varphi 2} \cos \varphi & =(2 f g h)^{1 / 2}, \\
u_{\varphi} \cos \varphi & =\left(u_{\varphi 1}^{2} \cos ^{2} \varphi+u_{\varphi 2}^{2} \cos ^{2} \varphi\right)^{1 / 2} \\
& =[2 g h(1+f)]^{1 / 2},
\end{aligned}
$$

where $f$ is the coefficient of friction between the elements, and $m$ is the mass of the debris element.

However, equation (14) does not consider the effect of atmospheric pressure. On the one hand, atmospheric pressure increases the frictional force, but; on the other hand, it produces a static and dynamic air pressure that impedes the movement of the debris element. An increase in $h$ of $\sim 5 \mathrm{~m}$ is sufficient to accurately reflect this effect because the pressure given by such a soil layer is approximately equal to the atmospheric pressure. Therefore, equation (14) is transformed to

$$
u_{\varphi} \cos _{\varphi}=\left[2 g(h+5)(1+f)^{1 / 2}\right] .
$$

The momentum theorem shows that $u_{\varphi} \partial_{m}=\partial I=i \partial F$ and $u_{\varphi}=i \partial F / \partial m$, where $i$ is the relative impulse, $\partial F$ is the

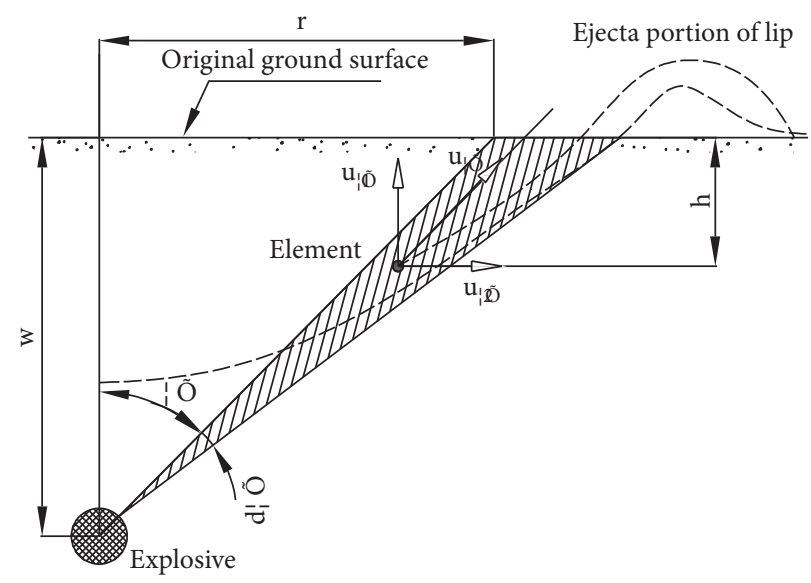

FIgURE 9: Schematic diagram of a debris element being thrown out of the crater.

area of contact between the explosive and the projectile cone element under consideration, and $\partial_{m}$ is the mass of the element.

$$
\begin{aligned}
\partial_{m} & =\pi k_{1}^{*} \rho_{0}\left(\frac{w^{3}}{\cos ^{3} \varphi}\right) \sin \varphi \mathrm{d} \varphi, \\
\partial F & =2 \pi R_{w}^{2} \sin \varphi \mathrm{d} \varphi, \\
i & =\frac{W \sqrt{2 \xi Q_{W}}}{4 \pi R_{W}^{2}},
\end{aligned}
$$

where $\mathrm{k}_{1}^{*} \approx 3 / 4, \rho_{0}$ is the density of the soil element, $Q_{W}$ is the specific energy of the explosive, and $\xi$ is the coefficient that determines the velocity distribution of the moving part of the explosive $(\xi<1)$. When the velocity is uniformly distributed, $\xi=1$. The impulse is calculated using

$$
\begin{aligned}
\frac{1}{2} W u_{w}^{2} & =\xi Q_{w} W, \\
W u_{w} & =4 \pi R_{w}^{2} i .
\end{aligned}
$$

The first equation of equation (17) indicates that the kinetic energy of the explosive weight is equal to its potential energy, and the second equation indicates that the change in kinetic energy of the explosive weight is equal to the impulse acting on its surface. From the momentum theorem and 
equation (16), $u_{w}$ is the velocity of the explosive element, and we obtain

$$
\begin{aligned}
u_{\varphi} & =i \frac{\partial F}{\partial m} \\
& =a \frac{\sqrt{Q_{w}}}{\rho_{0}} \frac{W}{w^{3}} \cos ^{3} \varphi, \quad a=\frac{\sqrt{2 \xi}}{2 \pi k_{1}^{*}} .
\end{aligned}
$$

If the center of gravity of the vertebral body is $1 / 4$ of the height, then we can substitute $(w+5) / 4$ for $H+5[18]$, and it is defined that $n=r / w=\tan \varphi$. Therefore, $\cos \varphi=1 / \sqrt{1+\tan ^{2} \varphi}$, where $r$ is the apparent radius.

Considering the effect of the buried depth and friction, the velocity given by equation (15) is equal to the velocity given by equation (18); thus, we obtain

$$
W=\frac{4 \rho_{0} \times 2.18 \sqrt{g}}{A} w^{3}\left(\frac{1+n^{2}}{2}\right)^{2}[1+B(w+5)] .
$$

Here, $A=2.18 a \sqrt{B Q_{w}}, B=\lambda \rho_{0} K_{V d}^{*} / Q_{w}(\gamma-1), \lambda$ is a constant, $\gamma$ is an adiabatic exponent, and $K_{V d}^{*}$ is the permeability coefficient that can be determined from reference tables [18]. The value of $A$ is determined through experiments. For medium explosives and moderate soil, $A=3,200 \mathrm{~kg} / \mathrm{m}^{3}, \rho_{0}=1300 \mathrm{k}_{3}$, and $k_{3}$ is a coefficient. Then,

$$
W=k_{3} w^{3}\left(\frac{1+n^{2}}{2}\right)^{2}(1+B w) .
$$

For medium explosives and moderate soil, $\rho_{0}=2000 \mathrm{~kg} / \mathrm{m}^{3}, K_{v d}^{*}=0.18 \mathrm{~m}^{3}$

$/ \mathrm{kg}, Q_{w}=4.5 \times 10^{5} \mathrm{~m} / \mathrm{kg}, \lambda=5$, and $\gamma=1.2$. These values were obtained from [18], and it can be calculated that $B=0.02 \mathrm{~m}^{-1}$.

When an explosive initiates on the ground, only a part of the energy is used to generate the crater; i.e.,

$$
W_{u}=\eta W_{t}
$$

where $W_{u}$ is the weight generating the crater, $\eta$ is the energy conversion coefficient, and $W_{t}$ is the total weight of the explosives. For explosions on or above the surface, the apparent and true craters are roughly coincident because most of the soil debris is blown out of the crater [38]. It can be assumed that $H_{a}=H_{t}=w$, where $H_{a}$ is the depth of the apparent crater, $H_{t}$ is the depth of the true crater, and $w$ is the depth of the explosive. The weight of the explosive used to generate the crater can be obtained by inputting the depth of the test into equation (20).

Table 10 lists the calculated results using equation (20) with different densities ranging from 2.26 to $2.39 \mathrm{~g} / \mathrm{cm}^{3}$. For densities $\rho_{1}$ and $\rho_{2}$, the calculated energy conversion coefficient is $\eta_{1}$ and $\eta_{2}$, respectively. The parameter $\bar{\eta}$ is the average of $\eta_{1}$ and $\eta_{2}, \overline{\eta_{\text {ave }}}$ is the average of $\overline{\eta_{1}}, \overline{\eta_{2}}, \overline{\eta_{3}}$, and $\overline{\eta_{4}}$; i.e., $\overline{\eta_{\text {ave }}}=\left(\overline{\eta_{1}}+\overline{\eta_{2}}+\overline{\eta_{3}}+\overline{\eta_{4}}\right) / 4=0.051$.

As indicated above, $\rho_{0}=1300 \mathrm{~K}_{3}$, the blasting index $n=r / w, \bar{n}=\left(n_{1}+n_{2}+n_{3}+n_{4}\right) / 4=2.74, \bar{n}$ is the average of $n_{\mathrm{i}} \quad\left(n_{\mathrm{i}}\right.$ is determined from Table 10$)$, and the value $B=0.02 \mathrm{~m}^{-1}$. Once these values are inserted into (20), the functional relationship for the craters generated by a contact
TABLE 10: Calculated results of energy conversion coefficient for different densities.

\begin{tabular}{lccccccc}
\hline Test $i$ & $\begin{array}{c}W \\
\text { (ton) }\end{array}$ & $\begin{array}{c}\text { Mean } D \\
(\mathrm{~m})\end{array}$ & $\begin{array}{c}\text { Mean } H \\
(\mathrm{~m})\end{array}$ & $n_{i}$ & $\eta_{1}$ & $\eta_{2}$ & $\overline{\eta_{i}}$ \\
\hline 1 & 1 & 4.520 & 0.945 & 2.39 & 0.017 & 0.018 & 0.0175 \\
2 & 3 & 10.000 & 1.500 & 3.33 & 0.073 & 0.077 & 0.075 \\
3 & 10 & 13.740 & 3.100 & 2.21 & 0.046 & 0.049 & 0.0475 \\
4 & 10 & 14.550 & 2.400 & 3.03 & 0.064 & 0.067 & 0.065 \\
\hline
\end{tabular}

explosion on the Gobi Desert surface using a large weight of TNT explosive can be expressed as follows:

$$
W=17.2477 k_{3} r^{3}(1+0.0073 r)(\mathrm{kg}) \text {. }
$$

In extreme cases, the surface explosion of 5,000 tons of explosives produces a crater with a diameter of 55m [6], and the value of $0.0073 r$ is a value of only 0.4 . When the parameter $r$ is small, $0.0073 r \ll 1$, and the value of $0.0073 r$ is negligible. Thus, the diameter of the crater generated by a contact explosion on the Gobi Desert surface can be predicted from

$$
\begin{aligned}
D & =2 r \\
& =2 \times \sqrt[3]{\frac{W}{17.2477 K_{3}}} \\
& =\sqrt[3]{\frac{602.9789 W}{\rho_{0}}}(\mathrm{~m}),
\end{aligned}
$$

where $r$ is the apparent radius of the crater in $m, W$ is the weight of the explosives in $\mathrm{kg}$, and $\rho_{0}$ is the density of the soil element in $\mathrm{kg} / \mathrm{m}^{3}$. The depth of the crater generated by a contact explosion on the Gobi Desert surface can be predicted from

$$
\begin{aligned}
H & =\frac{(D / 2)}{\bar{n}} \\
& =\frac{r}{\bar{n}}=\sqrt[3]{\frac{3.664 W}{\rho_{0}}}(\mathrm{~m}) .
\end{aligned}
$$

4.2. Evaluation of the Proposed Formulae. Table 11 lists the calculated results using the derived theoretical formulae, (23) and (24), for different densities ranging from 2.26 to $2.39 \mathrm{~g} / \mathrm{cm}^{3}$. For a density $\rho_{1}$, the calculated results are $D_{C 1}$ and $H_{C 1}$; for a density $\rho_{2}$, the results are $D_{C 2}$ and $H_{C 2}$. The ratios $D_{C 1} / D_{C 2}$ and $H_{C 1} / H_{C 2}$ are $\sim 1.019$. It can be inferred that the diameter and depth of the crater decrease slightly as the density increases, and it would increase significantly with an increase in the explosive mass.

Table 12 shows a comparison between the test data of the craters generated by explosions on the ground surface and the theoretically calculated values. Similarly, the calculated $D_{\mathrm{C}}$ value denotes the average of the calculated $D_{\mathrm{C} 1}$ and the calculated $D_{\mathrm{C} 2}$; the calculated $H_{\mathrm{C}}$ value is the average of the calculated $H_{\mathrm{C} 1}$ and the calculated $H_{\mathrm{C} 2}$. For the crater 
TABLE 11: Calculated results of the crater dimensions by different densities.

\begin{tabular}{lcccccc}
\hline$W$ (ton) & $D_{\mathrm{C} 1}(\mathrm{~m})$ & $H_{\mathrm{C} 1}(\mathrm{~m})$ & $D_{\mathrm{C} 2}(\mathrm{~m})$ & $H_{\mathrm{C} 2}(\mathrm{~m})$ & $D_{C 1} / D_{\mathrm{C} 2}$ & $H_{C 1} / H_{C 2}$ \\
\hline 1 & 6.436 & 1.174 & 6.316 & 1.153 & 1.019 & 1.018 \\
3 & 9.282 & 1.694 & 9.110 & 1.662 & 1.019 & 1.019 \\
10 & 13.866 & 2.530 & 13.610 & 2.480 & 1.019 \\
\hline
\end{tabular}

TABLE 12: Calculated results of the crater dimensions.

\begin{tabular}{lccccccc}
\hline Test $i$ & $W($ ton $)$ & Test $D(\mathrm{~m})$ & Test $H(\mathrm{~m})$ & $D_{\mathrm{C}}(\mathrm{m})$ & $H_{\mathrm{C}}(\mathrm{m})$ & Diameter deviation & Depth deviation \\
\hline 1 & 1 & 4.520 & 0.945 & 6.376 & 1.164 & $41.0 \%$ & $21.90 \%$ \\
2 & 3 & 10.000 & 1.500 & 9.196 & 1.678 & $-8.0 \%$ & $-1.90 \%$ \\
3 & 10 & 13.740 & 3.100 & 13.783 & 2.515 & $0.3 \%$ & $-18.40 \%$ \\
4 & 10 & 14.550 & 2.400 & & & $-5.2 \%$ & $5.40 \%$ \\
\hline
\end{tabular}

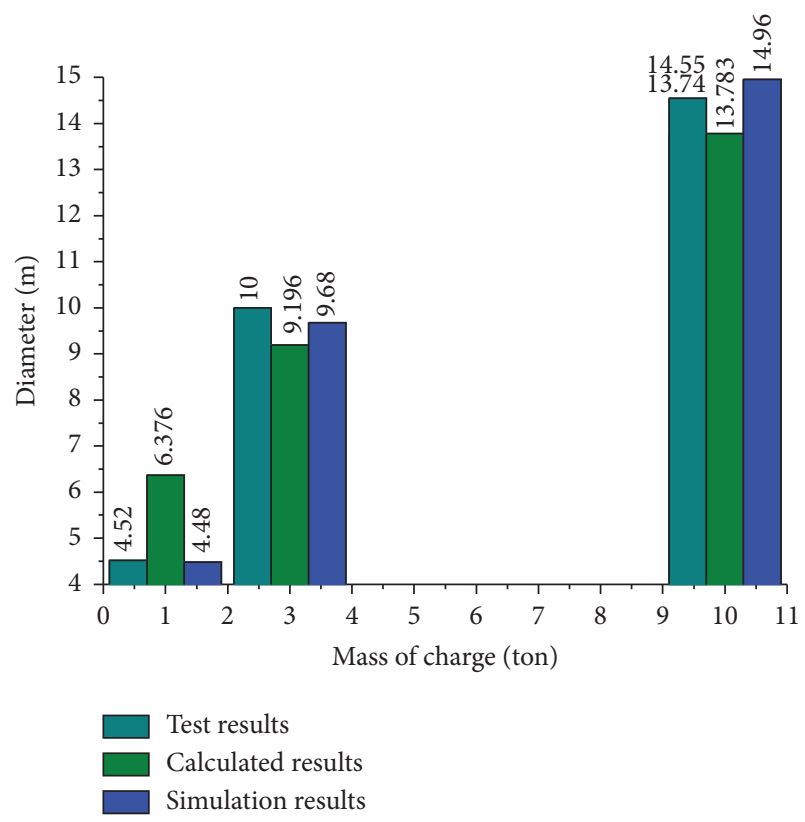

(a)

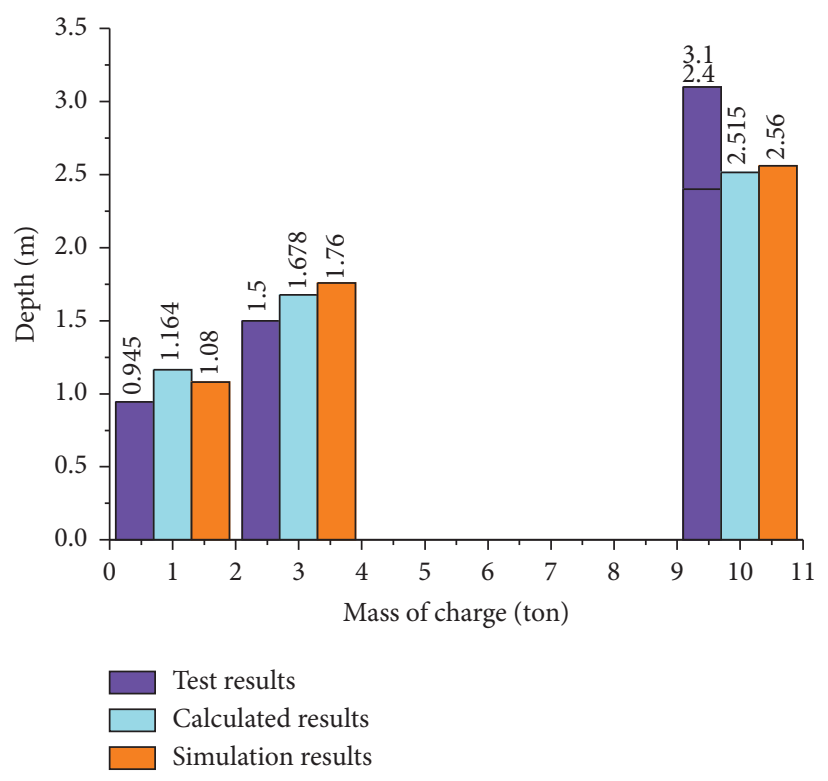

(b)

FIgURE 10: Comparison of crater dimension data obtained from field tests, numerical simulation, and theoretical analysis: (a) crater diameter and (b) crater depth.

diameter, the calculated diameters for the 3 tons and 10 tons of TNT were consistent with the test data, and the absolute error was less than $8 \%$. The deviation between the calculated and field test results is slightly greater for the 1-ton test because the influence of the adhesive force of the projectile in contact with the crater is not considered in equation (18) [18]. However, the calculated depth in the four tests is not consistent with the field test data because the falling of elements back into the crater was not considered in the theoretical derivation.

Statistical data related to craters formed using chemical explosives were collected prior to the 1940s [39] and did not contain precise information regarding the explosive type, size, shape, and ground characteristics. Even carefully controlled crater experiments produced deviations in crater dimensions of $10 \%$, and scatter in the range of $\pm 30 \%-40 \%$ was common. The calculation error using equations (23) and (24) is acceptable, as indicated in Table 12. Therefore, equations (23) and (24) can be used to accurately calculate the size of the craters generated by contact explosion on the Gobi Desert surface using a large charge weight. The diameter of the crater basically conforms to the explosion similarity law.

Figure 10 shows a comparison of the data in Table 5 and Table 11. Figure 10(a) is the comparison results for the crater diameter. Figure $10(\mathrm{~b})$ is the comparison results for the crater depth. It is obvious from Figure 10 that the field test results, numerical results, and theoretical results are basically consistent with each other when the mass of the TNT explosives is 3 tons and 10 tons. Compared with the field test and numerical simulation, the derived explicit formulae of equations (23) and (24) are more advantageous in terms of 
TABLE 13: Previous test data of large-scale surface explosion craters [6].

\begin{tabular}{|c|c|c|c|c|c|}
\hline No. & TS & $W$ (ton) & $S$ & $r(\mathrm{~m})$ & $H(\mathrm{~m})$ \\
\hline 5 & 2 & 5,000 & 1 & 55 & 21.4 \\
\hline 6 & 7 & 1,152 & 2 & 34.2 & 12 \\
\hline 7 & 2 & 1,013 & 2 & 34.4 & 14 \\
\hline 4 & 1 & 1,000 & 1 & 26.7 & 16.5 \\
\hline 1 & 3 & 901 & 1 & 35 & 12 \\
\hline 3 & 2 & 501 & 3 & 21 & 14.1 \\
\hline 2 & 2 & 500 & 3 & 20.9 & 7.9 \\
\hline 27 & 2 & 500 & 3 & 22.5 & 7.5 \\
\hline 31 & 2 & 330 & 1 & 22.2 & 9.4 \\
\hline 24 & 2 & 300 & 3 & 25.8 & 9.6 \\
\hline 12 & 2 & 280 & 2 & 26.7 & 14.1 \\
\hline 22 & 2 & 250 & 1 & 19.3 & 8.5 \\
\hline 28 & 2 & 200 & 3 & 13.5 & 3.5 \\
\hline 30 & 2 & 155 & 1 & 17.2 & 8.9 \\
\hline 29 & 2 & 150 & 2 & 21.3 & 10 \\
\hline 10 & 2 & 100 & 2 & 16.5 & 11 \\
\hline 11 & 2 & 100 & 2 & 17.5 & 10 \\
\hline 13 & 2 & 100 & 2 & 16.2 & 9 \\
\hline 14 & 2 & 100 & 2 & 17 & 10.8 \\
\hline 15 & 2 & 100 & 2 & 17.4 & 10.7 \\
\hline 21 & 2 & 100 & 1 & 15.2 & 7.2 \\
\hline 23 & 2 & 100 & 1 & 18.2 & 7.6 \\
\hline 25 & 7 & 100 & 2 & 14.2 & 6.62 \\
\hline 26 & 2 & 100 & 2 & 15.2 & 7 \\
\hline 32 & 2 & 100 & 1 & 18 & 6.6 \\
\hline 57 & 2 & 80 & 1 & 16 & 7.4 \\
\hline 39 & 2 & 50 & 1 & 11.9 & 5.5 \\
\hline 50 & 2 & 50 & 3 & 10 & 3.85 \\
\hline 52 & 2 & 50 & 3 & 10.8 & 3.4 \\
\hline 56 & 2 & 20 & 1 & 7.5 & 4.5 \\
\hline 55 & 2 & 15 & 3 & 6.6 & 2.28 \\
\hline 16 & 3 & 12 & 1 & 8 & - \\
\hline 17 & 2 & 10 & 1 & 6.75 & 3.25 \\
\hline 18 & 2 & 10 & 1 & 7.53 & 3.5 \\
\hline 19 & 2 & 10 & 1 & 7 & 4.75 \\
\hline 20 & 2 & 10 & 1 & 8.28 & 5.1 \\
\hline 33 & 2 & 10 & 2 & 7.3 & 4 \\
\hline 34 & 2 & 10 & 2 & 8.8 & 4.4 \\
\hline 35 & 2 & 10 & 2 & 7.35 & 4.53 \\
\hline 36 & 2 & 10 & 2 & 7.28 & 3.9 \\
\hline 37 & 2 & 10 & 2 & 7.02 & 3.03 \\
\hline 38 & 2 & 10 & 2 & 7.3 & 3.2 \\
\hline 42 & 2 & 10 & 2 & 7 & 3.95 \\
\hline 43 & 2 & 10 & 3 & 6.85 & 3.25 \\
\hline 45 & 2 & 10 & 3 & 5.1 & 1.9 \\
\hline 46 & 7 & 10 & 2 & 6.8 & 2.5 \\
\hline 47 & 2 & 10 & 2 & 7 & 3.2 \\
\hline 51 & 2 & 10 & 3 & 4.9 & - \\
\hline 58 & 2 & 10 & 1 & 7.25 & 4.28 \\
\hline 49 & 2 & 5 & 3 & 5 & 2.5 \\
\hline 40 & 2 & 1 & 2 & 3.4 & 1.55 \\
\hline 41 & 2 & 1 & 2 & 2.75 & 1.3 \\
\hline 44 & 2 & 1 & 3 & 3 & 1.3 \\
\hline 48 & 2 & 1 & 2 & 3.5 & 1.5 \\
\hline 53 & 2 & 1 & 3 & 3.65 & 0.86 \\
\hline 54 & 2 & 1 & 3 & 3 & 0.96 \\
\hline
\end{tabular}

Note. $r$ and $H$ are the crater radius and depth, respectively, counted from the free surface, No. denotes the number of the explosion, $W$ is the TNT equivalent of the explosion, TS is the code of the test site, and $S$ is the soil code. 


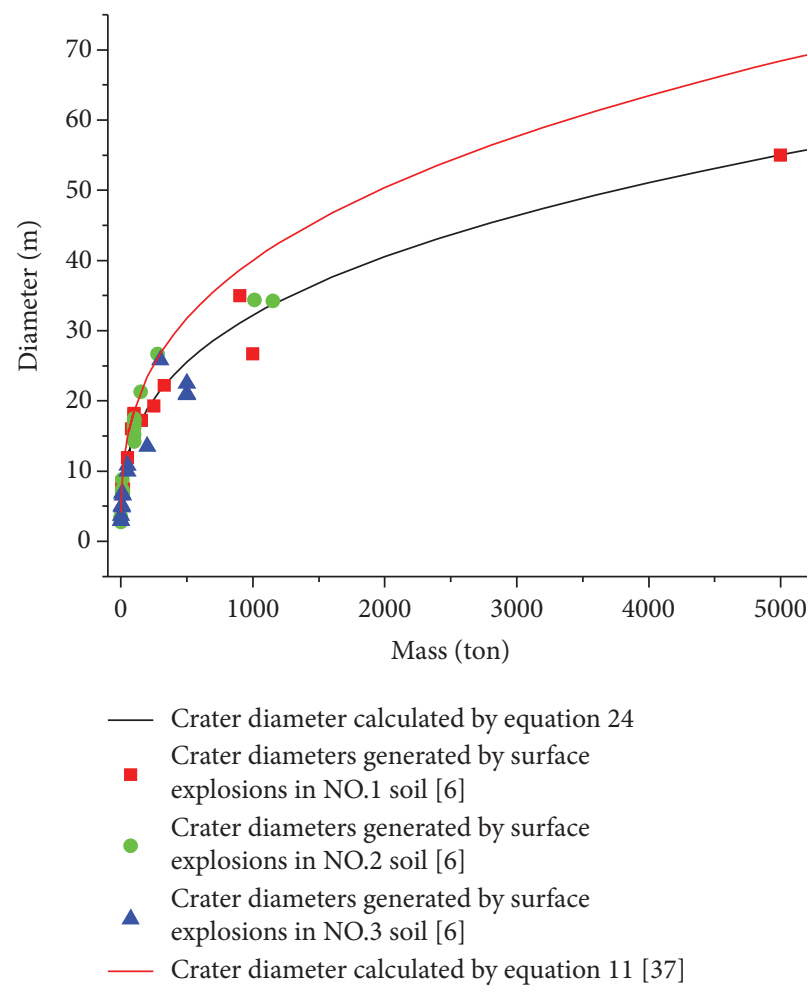

(a)

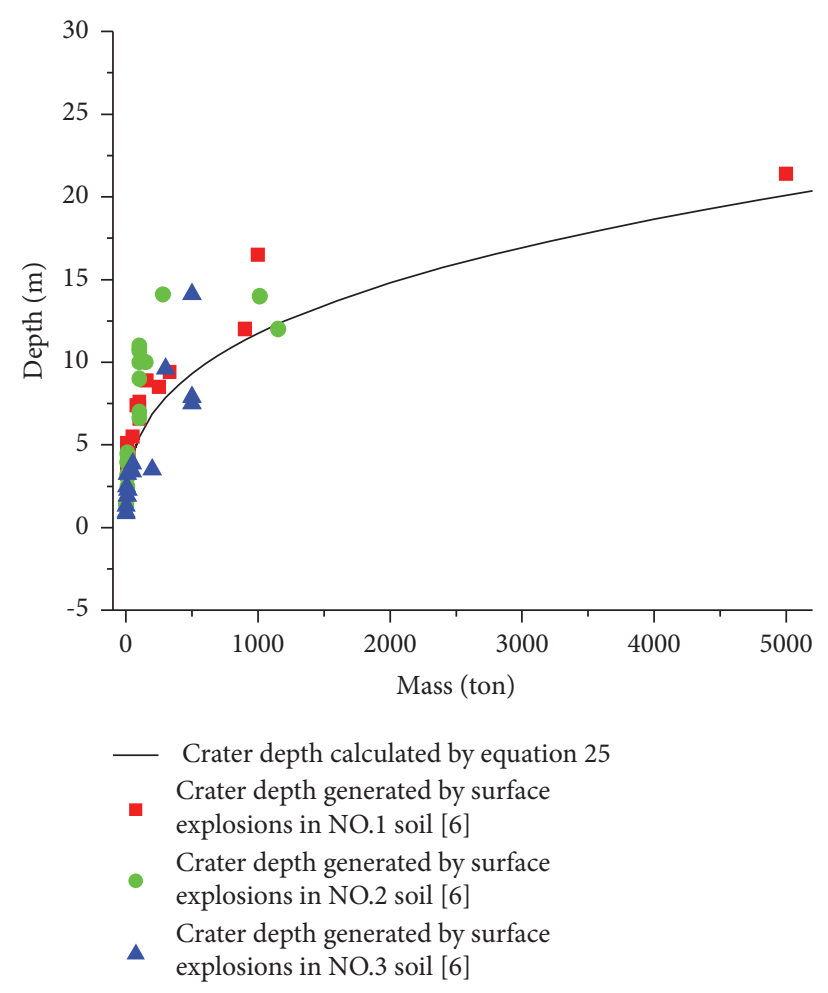

(b)

Figure 11: Comparison between the calculated crater dimensions and previous field test data.

cost and time. The diameter and depth of such craters can be calculated even if only the explosive equivalent and soil density are known.

4.3. Application of the Proposed Formulae and Energy Conversion Coefficient to Existing Large-Scale Surface Explosion Data. The derived formulae for calculating crater dimensions were applied to predict the existing crater data at different test sites [6]. Fifty-six large-scale surface explosion tests were conducted in three different soil types: soils No. 1 and No. 2 were soft soils with shallow and deep rocks and groundwater with a density of $1.6-1.9 \mathrm{~g} / \mathrm{cm}^{3}$, whereas soil No. 3 was weathered fractured rock with a density of $\sim 2.8 \mathrm{~g} /$ $\mathrm{cm}^{3}$. The TNT equivalent of the explosions (W) ranged from 1 to 5,000 tons. The test data for the explosion conditions and crater sizes are summarized in Table 13.

Figure 11 compares the calculated results with the data measured in the field tests. Figure 11(a) shows a comparison between the results obtained from equation (23) and the existing test data, as well as the results obtained from equation (10) for the crater radius. It can be observed that the radius of the crater generated by ground explosions from 1 ton to 5,000 tons of TNT in three different soil types is essentially scattered on both sides of the theoretical curve, thus proving the effectiveness and usability of equation (23). Figure 11(b) shows a comparison between the calculated results and existing test data for the crater depth. The overall trend of the data for the depth of craters is basically consistent with the theoretical curve. The correctness of equations (23) and (24) was confirmed again with the existing test data, which could be used to calculate the size of craters generated by contact explosion on the Gobi Desert surface using a large weight of explosive.

Similarly, the same method using the equation (20) detailed in Section 4.1 can be used to calculate the energy coefficient of the fifty-six large-scale surface explosion tests with different soil types. For a density of $1.6 \mathrm{~g} / \mathrm{cm}^{3}$ for soils No. 1 and No. 2, the total calculated average energy coefficient is 0.046 . For a density of $1.9 \mathrm{~g} / \mathrm{cm}^{3}$ for soils No. 1 and No. 2, the total calculated average energy conversion coefficient is 0.052 . Therefore, the confidence interval of the total calculated average energy coefficient is [0.046, 0.052]. In [40], the energy conversion coefficient of soft rock and a dry soil medium is 0.04 , which is outside the confidence interval. Sand and gravel can be considered moderately soft rock and dry soil medium, and an average energy coefficient surface explosion of 0.051 is more reliable for calculating large charge weights of explosives.

\section{Conclusion}

Four field contact explosion tests were conducted on the Gobi Desert surface with large TNT charge weights of 1 ton, 3 tons, and 10 tons (test conducted twice). Based on the text data, numerical simulations and theoretical analyses were conducted to analyze the dimensions of craters generated by contact explosions on the Gobi Desert surface using a large weight of explosives. The following conclusions were drawn in this study: 
(1) The dimensions (diameter and depth) of the crater are not linearly related to the mass of the explosive, and the crater parameters agree with the explosion similarity law.

(2) The influences of different parameters on the dimensions of cratering characteristics were demonstrated by the fine-mesh numerical simulation; the dispersion degree of the density, initiation method, and hydrotensile limit have only a slight influence on the dimensions of the crater induced by the contact explosion of large charge weight, while the shear modulus has a significant influence on the dimensions of the crater for this numerical model.

(3) Explicit theoretical formulae were derived for determining the diameter and depth of craters generated by explosions on the Gobi Desert surface. It was determined that these explicit formulae can be used to predict the dimensions of the craters generated by large amounts of explosives. An energy conversion coefficient was obtained, and its applicability was verified.

\section{Data Availability}

The data of this study are derived from the experimental results. All the data can be found in this manuscript. Researchers can use the data to verify that the results of an article replicate the analysis and conduct secondary analyses.

\section{Conflicts of Interest}

The authors declare that they have no conflicts of interest.

\section{Acknowledgments}

The authors acknowledge the financial support from the National Natural Science Foundation of China (No. 51978166, 51678403, and 51738011) and the Fundamental Research Funds for the Central Universities.

\section{References}

[1] F. Qin, S. Yang, L. Chen, J. Liu, and Y. Zhang, "Analysis on the building damage, personnel casualties and blast energy of the 8.12 explosion in Tianjin port," China Civil Engineering Journal, vol. 50, no. 3, pp. 12-18, 2017.

[2] D. Chen, L. Chen, H. Yi, R. Xu, Y. Liu, and F. Qin, "Analysis of the power and disaster consequences of " 3.21 " explosion accident in the chemical industry park of Xiangshui, Yancheng city," Journal of Disaster Prevention and Mitigation Engineering, vol. 50, no. 3, pp. 12-18, 2019.

[3] H. J. Pasman, C. Fouchier, S. Park, N. Quddus, and D. Laboureur, "Beirut ammonium nitrate explosion: are not we really learning anything?” Process Safety Progress, vol. 39, pp. 1-18, 2020.

[4] Dynamic Effectsof the Structural Division of the American Society of Civil Engineers, Design of Structures to Resist Nuclear Weapons Effects, American Society of Civil Engineers, Reston, VA, USA, 2nd ed. edition, 1983.
[5] B. F. Murphey and L. J. Vortman, "High-explosive craters in desert alluvium, tuff, and basalt," Journal of Geophysical Research, vol. 66, no. 10, pp. 3389-3404, 1961.

[6] V. V. Adushkin and B. D. Khristoforov, "Craters of large-scale surface explosions," Combustion, Explosion, and Shock Waves, vol. 40, no. 6, pp. 674-678, 2004.

[7] R. D. Ambrosini and B. M. Luccioni, "Craters produced by explosions on the soil surface," Journal of Applied Mechanics, vol. 73, no. 6, pp. 890-900, 2006.

[8] D. Milo and k. Nordy, "Cratering experience with chemical and nuclear explosives," Engineering with nuclear explosives, pp. 51-74, 1964.

[9] K. Ohkubo, M. Beppu, T. Ohno, and K. Satoh, "Experimental study on the effectiveness of fiber sheet reinforcement on the explosive-resistant performance of concrete plates," International Journal of Impact Engineering, vol. 35, no. 12, pp. 1702-1708, 2008.

[10] R. D. Ambrossini, B. M. Luccioni, R. F. Danesi, J. D. Riera, and M. M. Rocha, "Size of craters produced by explosive charges on or above the ground surface," Shock Waves, vol. 12, pp. 69-78, 2002.

[11] B. Luccioni, D. Ambrosini, G. Nurick, and I. Snyman, "Craters produced by underground explosions," Computers \& Structures, vol. 87, no. 13, pp. 66-73, 2009.

[12] D. Anirban, "Numerical simulation of surface explosions over dry, cohesionless soil," Computers and Geotechnics, vol. 43, pp. 72-79, 2012.

[13] J. B. Knox and R. W. Terhune, "Calculation of explosionproduced craters," Engineering with nuclear explosives, vol. 70, pp. 75-98, 1964.

[14] J. W. Bull and C. H. Woodford, "The numerical analysis and modelling of repaired runways following chemical explosive crater formation," Numerical Analysis and Modelling of Composite Materials, Springer, Berlin, Germany, pp. 128-151, 1996.

[15] Z. L. Wang, H. Konietzky, and R. Y. Huang, "Elastic-plastichydrodynamic analysis of crater blasting in steel fiber reinforced concrete," Theoretical and Applied Fracture Mechanics, vol. 52, no. 2, pp. 111-116, 2009.

[16] W. E. Baker, P. A. Cox, P. S. Westine, J. J. Kulesz, and R. A. Strehlow, Explosion Hazards and Evaluation, Elsevier, Amsterdam, Netherlands, 1983.

[17] P. S. Westine, "Explosive cratering," Journal of Terramechanics, vol. 7, no. 2, pp. 9-19, 1970.

[18] G. I. Pokroyski and A. A. Tsernigovskii, Calculation of Charges of Multiple-Blasts for Throw, 1960.

[19] J. Henrych and R. Major, The Dynamics of Explosion and its Use, Elsevier/North Holland, Hoboken NJ, USA, 1979.

[20] A. J. Chabai, "On scaling dimensions of craters produced by buried explosives," Journal of Geophysical Research, vol. 70, no. 20, pp. 5075-5098, 1965.

[21] J. E. Hill and J. J. Gilvarry, "Application of the Baldwin crater relation to the scaling of explosion craters," Journal of Geophysical Research, vol. 61, no. 3, pp. 501-511, 1956.

[22] R. M. Schmidt, "Some recent advances in the scaling of impact and explosion cratering," International Journal of Impact Engineering, vol. 5, pp. 543-560, 1987.

[23] J. A. Cheney, "AMERICAN literatureon geotechnical centrifuge modeling 1931-1984," in Proceedings of the Symposium on Recent Advances in Geotechnical Centrifuge Modeling, College of Engineering, Davis, CA, USA, July 1984.

[24] R. M. Schmidt, "Centrifuge simulation of the JOHNIE BOY 500 ton cratering event," in Proceedings of the Lunar and 
Planetary Science Conference, Houston, TX, USA, March 1978.

[25] R. M. Schmidt and K. A. Holsapple, "Centrifuge crater scaling experiments i, dry granular soils," Rep. DNA 4568F, Defense Nuclear Agency, Washington, D.C., USA, 1978.

[26] R. M. Schmidt and K. A. Holsapple, "Centrifuge crater scaling experiments II, Material strength effects," Rep. DNA 4999Z, Defense Nuclear Agency, Washington, D.C, USA, 1979.

[27] K. C. Brownell and W. A. Charlie, "Centrifuge modeling of explosion-induced craters in unsaturated sand," DTIC, Fort Belvoir, VA, USA, DTIC Document, 1992.

[28] C. Hansen and R. Y. S. Pak, "Centrifuge characterization of buried, explosive-induced soil ejecta kinematics and crater morphology," Journal of Dynamic Behavior of Materials, vol. 2, no. 3, pp. 306-325, 2016.

[29] China architectural design and research institute, The Outline of the Overall Plan of Alxa Left Banner in Inner Mongolia Province, china (2005-2020), China Architecture \& Building Press, Beijing, China, 2005.

[30] Autodyn, Interactive Non-linear Dynamic Analysis Software, Century Dynamics Inc, New York, NY, USA, 2002.

[31] G. F. C. Rogers and Y. R. Mayhew, "Thermodynamic and transport properties of fluids," Fluid Phase Equilibria, vol. 83, no. 2, pp. 85-92, 1994.

[32] E. Lee, M. Finger, and W. Collins, "JWL Equation of State coefficients for high explosives," UCID-16189, 1973.

[33] G. R. Johnson and T. J. Holmquist, "An improved computational constitutive model for brittle materials," AIP Conf. Proc, vol. 309, pp. 981-984, 1994.

[34] L. Laine and A. Sandvik, "Derivation of mechanical properties for sand," in Proceedings of the 4th Asia-Pacific Conference on Shock and Impact Loads on Structures 4th SILOS,CI-Premier LTD, pp. 361-367, Singapore, September 2001.

[35] H. Gercek, "Poisson's ratio values for rocks," International Journal of Rock Mechanics and Mining Sciences, vol. 44, no. 1, pp. 1-13, 2007.

[36] T. Sun, G. Chen, B. Wang, and L. I. Xiaojun, "Experimental research OF effect OF granule shape ON shear modulus and damping ratio OF gravel," Chinese Journal of Rock Mechanics and Engineering, vol. 33, no. Supp.2, pp. 4211-4217, 2014.

[37] G. F. Kinney and K. Graham, Explosive Shocks in Air, Springer-Verlag, Berlin, Germany, 2nd ed. edition, 1985.

[38] UFC 3-340-01, Design and Analysis of Hardened Structures to Conventional Weapon Effects, The Departments of the Army, Washington, DC, USA, 1998.

[39] J. W. Bull and C. H. Woodford, "Camouflets and their effects on runway supports," Computers \& Structures, vol. 69, no. 6, pp. 695-706, 1998.

[40] E. R. Crawford, C. J. Higgins, and E. H. Bultmann, The Air Force Manual for Design and Analysis of hardened Structures, US Air Force Weapons Laboratory, Washington, DC, USA, 1974. 